\title{
Free and Forced Vibration Characteristics Analysis of a Multispan Timoshenko Beam Based on the Ritz Method
}

\author{
Cong Gao, ${ }^{1}$ Fuzhen Pang, ${ }^{1}$ Haichao Li $\left(\mathbb{D},{ }^{1}\right.$ Hongfu Wang, ${ }^{1}$ Jie Cui, ${ }^{2}$ and Jisi Huang ${ }^{3}$ \\ ${ }^{1}$ College of Shipbuilding Engineering, Harbin Engineering University, Harbin 150001, China \\ ${ }^{2}$ College of Naval Architecture and Ocean Engineering, Jiangsu University of Science and Technology, Zhenjiang 212000, China \\ ${ }^{3}$ China National Intellectual Property Administration, Beijing 100088, China
}

Correspondence should be addressed to Haichao Li; lihaichao@hrbeu.edu.cn

Received 27 April 2021; Revised 21 June 2021; Accepted 2 July 2021; Published 13 July 2021

Academic Editor: S. Mahdi S. Kolbadi

Copyright (C) 2021 Cong Gao et al. This is an open access article distributed under the Creative Commons Attribution License, which permits unrestricted use, distribution, and reproduction in any medium, provided the original work is properly cited.

The uniform formulation of dynamic vibration analysis of multispan beams is presented by using an efficient domain decomposition method in this paper. Firstly, the structure is divided into several equal sections based on domain decomposition method. Next, the artificial spring is used to simulate complex boundaries and continuity condition of multispan beam. Finally, the admissible displacement functions are expanded through Jacobi orthogonal polynomials, and the free and forced vibration characteristics of multispan beam structures can be obtained by using Rayleigh-Ritz method. Results for various boundary conditions, ratios of thickness to length $(h / L)$, numbers, and stiffness of supporting springs are presented. It is clearly shown that accurate solutions can be obtained by using the proposed method, and this study extends the application range of the Jacobi polynomials-Ritz method. In addition, the research results of this paper can provide data support for engineers such as bridge designers to design multispan bridges.

\section{Introduction}

Multispan beam structure, as a basic component, has been widely used in areas such as aviation, bridge, ship, and other infrastructure because of its unique mechanical properties. This kind of structure is usually exposed to complex environment in the actual engineering application, which leads to being subjected to various environmental loads. In addition, the structure composition is relatively complex, and the traditional method is difficult and inefficient to simulate arbitrary boundary conditions. Therefore, the accurate method can be proposed to analyze of vibration characteristics of multispan beam structure has the important engineering value for guiding its structure design.

The bending vibration problems of beam structures mainly include Euler-Bernoulli beam, shear beam, Rayleigh beam, and Timoshenko beam [1]. Much effort has been dedicated to investigating the vibration characteristics of various structures in recent years. The main research methods include variational iteration method [2, 3], differential quadrature method $[4,5]$, transfer matrix method [6], Ritz method [7, 8], domain decomposition method [9-11], finite volume method [12], and finite element method [13-15]. In the framework of Euler-Bernoulli beam theory, Chen et al. [16] put forward an energy finite element method (EFEM) to solve the high-frequency vibration response of beams with axial force. Considering the influence of nonuniform cross section, Sinir et al. [17] carried out the free and forced vibration characteristics of FGM Euler-Bernoulli beam by employing differential quadrature method (DQM). According to the Timoshenko beam theory, Akbas [18] investigated the forced vibration characteristics of axially functionally graded beams, in which the effects of material and geometric parameters are considered. The free and forced vibration of variable thickness functionally graded beam were carried out by Xiang and Yang [19], who developed Lagrange interpolation polynomials to solve the dynamic equation. Wu and Chen [20] dealt with the free and forced vibration behaviors of laminated composite beams based on higher-order zig-zag 
theory, where the transverse shear stress is introduced into the equation of motion by using Hamilton's principle. More studies corresponding to the vibration characteristics of single-span beam can be found in [21-25].

With regard to multispan beam, based on the Euler-Bernoulli beam theory, Johansson et al. [26] deduced the closed-form dynamical solution of stepped multispan Bernoulli-Euler beam under concentrated moving loads. Fakhreddine et al. [27] performed nonlinear free and forced vibrations of multispan beam by means of single-mode approach, in which the formula derivation is in the framework of Hamilton's principle. Considering the influences of the boundary condition and damping, Ghannadiasl and Ajirlou [28] utilized the analytical method to analyze the forced vibration of multispan Euler-Bernoulli beams according to dynamic Green function formulation. Based on the Timoshenko beam theory, Chen et al. [29] demonstrated the application of the transfer matrix method for free and forced vibration analysis of multistep beams, where the forced vibration response was obtained on account of the modal superposition method. Besides, Lin and Chang [30] and Liu et al. [31] also employed the transfer matrix method to investigate the vibration characteristics of multispan beams. Lee [32] dealt with the free vibration characteristics of multispan beams for different dimension ratios and numbers of sections under different boundary conditions by using the pseudospectral method. In addition, the dynamic stiffness method was applied to investigate the free and forced vibration of multiple FGM multispan beams by Lien et al. [33], who considered the effect of cracks parameters on vibration characteristics of the FGM beams. Lv et al. [34] put to use the improved Fourier series approach and Rayleigh-Ritz method to analyze the vibration characteristics of multispan curved Timoshenko beams with general boundary restraints. Many of the studies in regard to multispan Timoshenko beam have been well documented in the excellent reviews of Yesilce [35-37] and his coworkers, who applied the secant method to study the free and forced vibration of multispan beam. According to the assumed mode method, Zhao et al. [38, 39] illustrated the free vibration solutions of multispan Timoshenko beams, where the vibration mode of the beam was modified by using the interpolation function, and the equations of motion of the structure were established by applying Hamilton's principle. Without any other assumptions, Lin and Tsai [40] performed the exact solutions of the multispan beam with multiple spring-mass systems, where the natural frequencies and corresponding modes were obtained from the differential equations of motion of the structure. Apart from the aforementioned beam theories, in order to investigate the free vibrations of multispan beam, Yesilce [41, 42] conducted numerous studies by using the secant method according to the Reddy-Bickford beam theory.

From the above analysis, it can be seen that the published literature has abundant research methods for the free vibration and forced vibration characteristics of single-span beam structures; however, there is a relative lack of research on the vibration characteristics of multispan beam structures, especially for forced vibration characteristics. In addition, the vibration response law of multispan beam under complex boundary conditions is not clear yet, and the semianalytical methods for the vibration characteristics of multispan beam structures need to be further enriched. According to this, the study aims at conducting the free and forced vibration solutions of multispan beam structure subject to complex boundary restraints.

Previously, the author has conducted the free vibration characteristics of spherical shell structures [43]; the multisegment partitioning, artificial spring technology, and Jacobi orthogonal polynomials are introduced to ensure the convergence and validity of the present method. According to the previous publication, several transversal displacement springs are arranged on the structure to represent the intermediate elastic support, and the forced vibration characteristics of the structure are solved by introducing the work done by the external concentrated load in this study. Finally, the parametric study of free and forced vibration characteristics of multispan beams is carried out.

\section{Theoretical Formulations}

2.1. Description of the Timoshenko Beam. Figure 1 displays the analytical model of multispan Timoshenko beam; $L, b$, and $h$, respectively, denote the length, width, and thickness of the structure. The Timoshenko beam differential equations of motion consist of two partial differential equations that can be obtained from literature [44]:

$$
\begin{array}{r}
\rho A \omega^{2} w(x)-\kappa G A\left(\frac{\partial \theta(x)}{\partial x}-\frac{\partial^{2} w(x)}{\partial x^{2}}\right)=0, \\
\rho I \omega^{2} \theta(x)-\kappa G A\left(\theta(x)-\frac{\partial w(x)}{\partial x}\right)+E I \frac{\partial^{2} \theta(x)}{\partial x^{2}}=0,
\end{array}
$$

where $\rho, E$, and $G$ are the density, Young's modulus, and extension rigidity, accordingly. $A$ and $I$, respectively, represent the area of the cross section and the area moment of inertia, and $\kappa$ denotes the shear correction factor which is assumed to be 5/6 during the study [45].

The bending moment $M(x)$ and transverse shearing forces $V(x)$ can be can be written as

$$
\begin{aligned}
& M(x)=E I \frac{\partial \theta(x)}{\partial x} \\
& V(x)=-\kappa G A\left(\theta(x)-\frac{\partial w(x)}{\partial x}\right) .
\end{aligned}
$$

The Timoshenko beam boundary restraints can be expressed as

$$
\begin{array}{ll}
k_{0} w(x)=-V(x), K_{0} \theta(x)=M(x), & \text { at } x=0, \\
k_{L} w(x)=V(x), K_{L} \theta(x)=-M(x), & \text { at } x=L,
\end{array}
$$

where $k_{0}$ and $k_{L}$, respectively, represent the transversal displacement constraint springs and $K_{0}$ and $K_{L}$ are the rotational constraint springs at ends $x=0$ and $x=L$, which can be shown in Figure 1. It is possible to simulate different boundary conditions by setting the spring stiffness value. By 


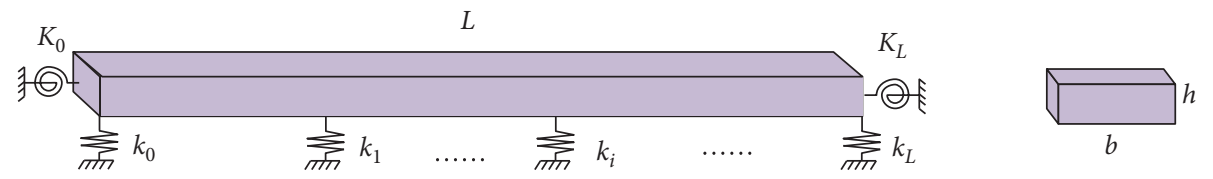

FIgURE 1: Calculation model of multispan beam structure.

changing the stiffness value of the supporting spring $\left(k_{t}\right)$ at the middle elastic support of the multispan beam structure, different elastic support conditions of the multispan beam can be simulated, assuming that there are $r$ supporting springs. The boundary conditions are given by

$$
\begin{array}{r}
\operatorname{clamped}(C): \theta=0, w=0, \\
\operatorname{pinned}(P): M=0, w=0, \\
\text { free }(F): M=0, V=0, \\
\operatorname{siding}(S): \theta=0, V=0 .
\end{array}
$$

In this paper, a multispan beam model is presented based on the domain decomposition method, as shown in Figure 2, assuming that the structure is divided into $H$ segments, where the $i$ th segment is coupled to $i+1$ th segment by a transversal displacement constraint spring $\left(\bar{k}_{i, i+1}\right)$ and a rotational constraint spring $\left(\bar{k}_{i, i+1}\right)$. In general, the connective spring stiffness is set to infinity to indicate the direct strong coupling between the two segments.

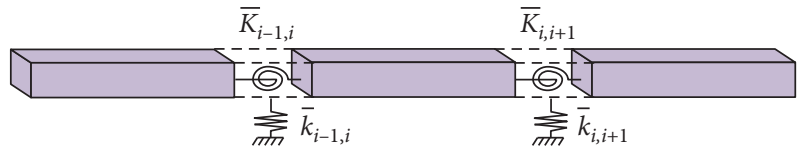

FIGURE 2: Diagram of multispan beam structure partition.

2.2. Admissible Displacement Functions Based on the Jacobi-Ritz Method. In this study, the admissible displacement functions are expanded through Jacobi orthogonal polynomials based on the multisegment partitioning technique $[46,47]$. The unified Jacobi orthogonal polynomials are set in the range of $\phi \in[-1,1]$, and the Jacobi polynomial can be transformed into Legendre polynomials $(\alpha=\beta=0)$, Chebyshev polynomials of first kind $(\alpha=\beta=-0.5)$, and Chebyshev polynomials of second kind $(\alpha=\beta=0.5)$ by setting the values of two Jacobi parameters $\alpha$ and $\beta$. The recurrence formulas of Jacobi polynomials are given by

$$
\begin{aligned}
P_{0}^{(\alpha, \beta)}(\phi)= & 1, \\
P_{1}^{(\alpha, \beta)}(\phi)= & \frac{\alpha+\beta+2}{2} \phi-\frac{\alpha-\beta}{2}, \\
P_{i}^{(\alpha, \beta)}(\phi)= & \frac{(\alpha+\beta+2 i-1)\left\{\alpha^{2}-\beta^{2}+\phi(\alpha+\beta+2 i)(\alpha+\beta+2 i-2)\right\}}{2 i(\alpha+\beta+i)(\alpha+\beta+2 i-2)} P_{i-1}^{(\alpha, \beta)}(\phi) \\
& -\frac{(\alpha+i-1)(\beta+i-1)(\alpha+\beta+2 i)}{i(\alpha+\beta+i)(\alpha+\beta+2 i-2)} P_{(i-2)}^{(\alpha, \beta)}(\phi),
\end{aligned}
$$

where $\alpha, \beta>-1$ and $i=2,3, \ldots$.

Therefore, the displacement function components of multispan beam structure based on Jacobi polynomials are shown as follows:

$$
\begin{aligned}
& w(x)=\sum_{m=0}^{M} A_{m} P_{m}^{(\alpha, \beta)}(x) e^{i \omega t}, \\
& \theta(x)=\sum_{m=0}^{M} B_{m} P_{m}^{(\alpha, \beta)}(x) e^{i \omega t},
\end{aligned}
$$

where $A_{m}$ and $B_{m}$ signify the Jacobi expansion coefficients and $M$ is the highest degrees of $m$.

The parameters such as velocity and acceleration can be obtained by deriving the displacement function one by one. Therefore, the main task of the whole solution process is to solve for the unknown Jacobi expansion coefficients.
2.3. Solution Procedure Based on the Hamilton Principle. Firstly, the energy description of the system is performed to find out the strain energy $U^{i}$, kinetic energy $T^{i}$, potential energy $V$, and work done by external load $W_{e}$ for each partition under this system, respectively, and then the eigenvalue equation of multispan beam vibration is obtained based on Hamilton's principle.

The $i$ th segment strain energy can be shown as follows:

$$
U^{i}=\frac{1}{2} \int_{0}^{L_{i}} E I\left(\frac{\partial \theta(x)}{\partial x}\right)^{2} \mathrm{~d} x+\frac{1}{2} \int_{0}^{L_{i}} \kappa G A\left(\theta-\frac{\partial w(x)}{\partial x}\right)^{2} \mathrm{~d} x .
$$

The ith segment kinetic energy of the structure can be expressed as 


$$
T^{i}=\frac{1}{2} \rho A \omega^{2} \int_{0}^{L_{i}} w(x)^{2} \mathrm{~d} x+\frac{1}{2} \rho I \omega^{2} \int_{0}^{L_{i}} \theta(x)^{2} \mathrm{~d} x .
$$

The structural potential energy is divided into three parts, including the boundary spring potential energy $V_{b}$, the connective spring potential energy $V_{s}$, and the supporting spring potential energy $V_{c}$. The boundary potential energy for the multispan beam can be expressed as

$$
V_{b}=\frac{1}{2}\left\{\left[k_{0} w(x)^{2}+K_{0}\left(\frac{\partial w(x)}{\partial x}\right)^{2}+K_{0} \theta(x)^{2}\right]_{x=0}+\left[k_{L} w(x)^{2}+K_{L}\left(\frac{\partial w(x)}{\partial x}\right)^{2}+K_{L} \theta(x)^{2}\right]_{x=L}\right\} .
$$

The potential energy in connective springs $\left(\bar{k}_{i, i+1}, \bar{k}_{i, i+1}\right)$ can be expressed as

$$
V_{s}=\sum_{i=1}^{n-1} \frac{1}{2}\left\{\bar{k}_{i, i+1}\left(w(x)^{i}-w(x)^{(i+1)}\right)^{2}+\bar{k}_{i, i+1}\left(\frac{\partial w(x)^{i}}{\partial x}-\frac{\partial w(x)^{(i+1)}}{\partial x}\right)^{2}+\bar{k}_{i, i+1}\left(\theta(x)^{i}-\theta(x)^{(i+1)}\right)^{2}\right\}
$$
below:

The potential energy in supporting springs is shown as

$$
V_{c}=\sum_{t=1}^{r} \frac{1}{2} k_{t} w(x)^{2}
$$

Therefore, the total potential energy of the constraint conditions for the multispan beam can be defined as

$$
V=V_{b}+V_{s}+V_{c}
$$

The work done by the external concentrated load can be written as

$$
W_{e}=\int_{0}^{L} F \delta\left(x-x_{0}\right) w(x, t) \mathrm{d} x,
$$

where $\delta$ is the Dirac function (unit impulse function), $F$ is the amplitude of the external concentrated load, and $x_{0}$ is the position of the action point.

The Lagrangian energy function $\mathscr{L}$ can be presented as

$$
\mathscr{L}=\sum_{i=1}^{H}\left(T^{i}-U^{i}\right)-V .
$$

By differentiating the unknown Jacobi expansion coefficients of (14), one can obtain

$$
\frac{\partial \mathscr{L}}{\partial \vartheta}=0, \quad \vartheta=A_{m}, B_{m}
$$

The multispan beam dynamic characteristic equation can be expressed as

$$
\left(\mathbf{K}-\omega^{2} \mathbf{M}\right) \mathbf{Q}=\mathbf{F}
$$

where $\mathbf{K}, \mathbf{M}$, and $\mathbf{Q}$ denote the stiffness matrix, mass matrix, and Jacobi coefficients matrix, respectively. The natural frequency and vibration modes for the multispan beam can be obtained by solving equation (16).
The unknown Jacobi coefficients matrix of the multispan beam structure under arbitrary circular frequency $(\omega)$ excitation can be expressed as

$$
\mathbf{Q}=\left(\mathbf{K}-\omega^{2} \mathbf{M}\right)^{-1} \mathbf{F} \text {. }
$$

By substituting the results of the above equation into equations (14) and (15), the vibration characteristics of the multispan beam structure can be obtained.

\section{Numerical Examples and Discussion}

The general boundary conditions clamped, free, pinned, and sliding are denoted by first alphabet C, F, P, and S, respectively. Unless otherwise specified, in this study, the material properties and geometrical dimensions are as follows: $E=210 \mathrm{GPa}, \rho=7800 \mathrm{~kg} / \mathrm{m}^{3}, \nu=0.3, M=8, \alpha=0.5$, $\beta=0.5, H=4 ; L=1 \mathrm{~m}, b=0.04 \mathrm{~m}$, and $h=0.02 \mathrm{~m}$. The nondimensional frequency is expressed as $\Omega=\sqrt{\omega L^{2} \sqrt{\rho A / E I}}$.

3.1. Convergence and Validity Study. In this section, the fundamental purpose is to check the reliability and the convergence of the current method. The parameters of boundary springs and connective springs decide boundary constrain condition and continuity condition. As mentioned above, the domain decomposition technique is utilized in current method; therefore, the convergence of algorithmic program is betting on the amount of number of segments and Jacobi parameters.

Figure 3 exhibits the nondimensional frequency parameters of multispan beam structure with different boundary parameters. The boundary condition and continuity condition changing from free condition to clamped condition with the spring stiffness varies from $10^{-11}$ to $10^{11}$. We can easily get that the stiffness values can be selected in the range of $10^{8} \sim 10^{11}$ for clamped boundary condition and the stiffness value is obviously to choose 


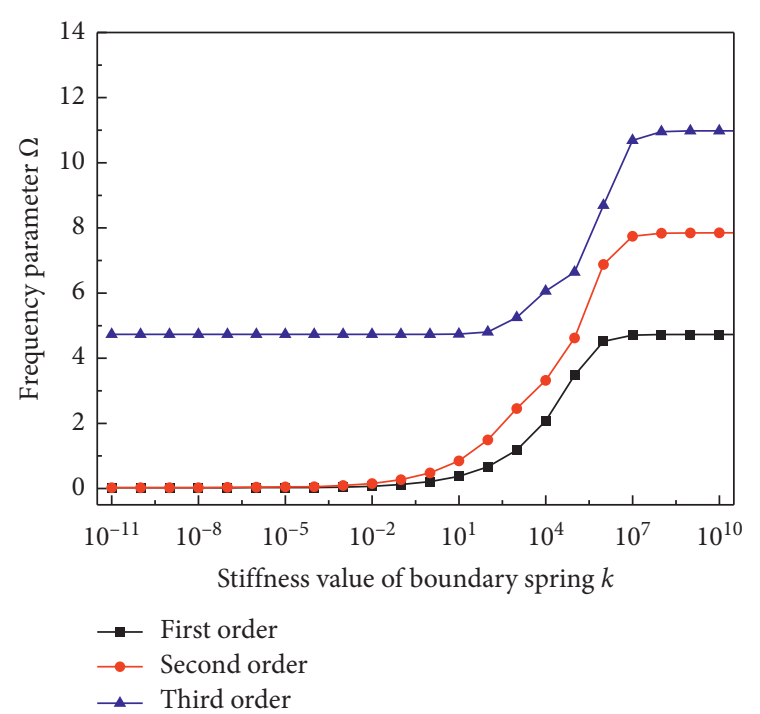

(a)

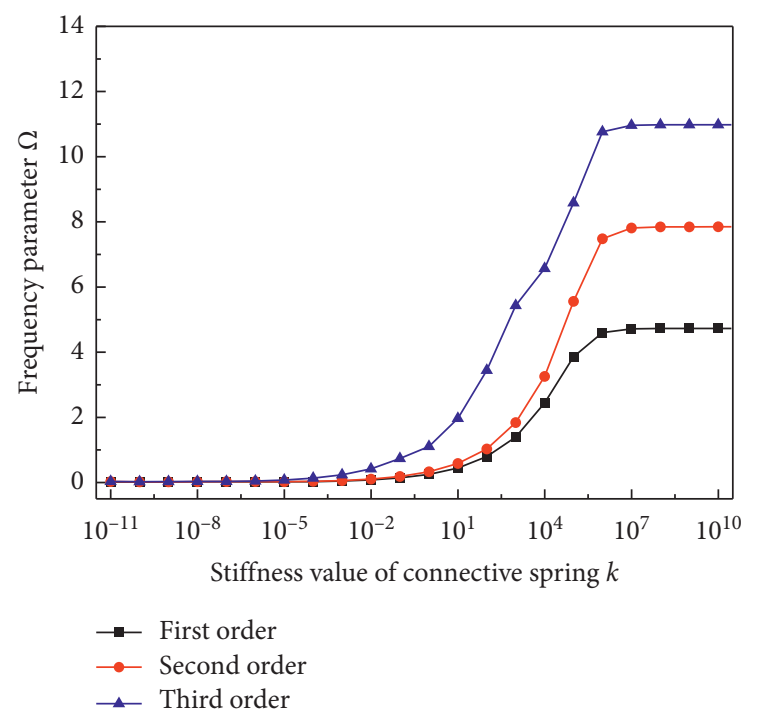

(c)

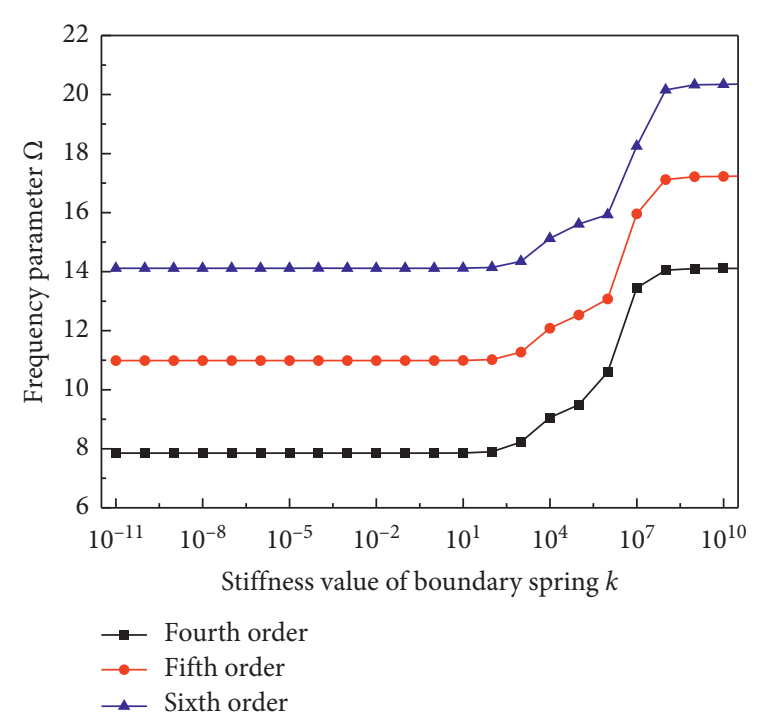

(b)

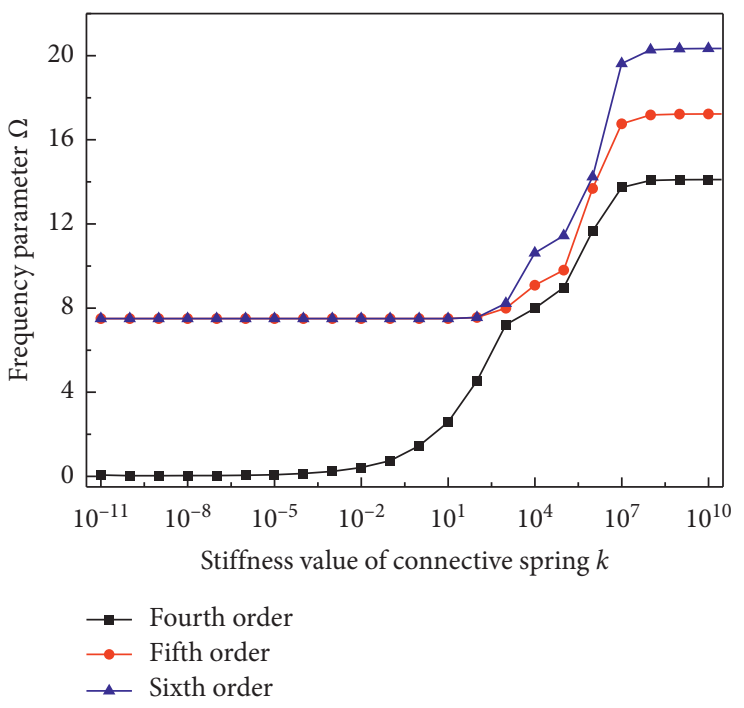

(d)

FIGURE 3: Frequency parameters $\Omega$ of multispan beam with different boundary parameters.

zero for free boundary condition. Whether it is a boundary spring or connective spring, it is apparently that the nondimensional frequency parameter increases rapidly with the spring value increasing in the range of $10^{1} \sim 10^{7}$. As mentioned above, the connective spring stiffness is generally set to infinity to indicate the strong coupling between the two segments. Thus, all boundary conditions of multispan beam structure used in this paper are displayed in Table 1.

Figure 4 displays the variation of nondimensional results with number of segments. It is evident to see that the great convergence can be obtained when the number of segments no less than 3 , which means that the high number of segments is not necessary. Therefore, the number of sections is chosen as 4 in this paper.

Next, convergence analysis of nondimensional frequency parameters $\Omega$ in relation to truncation terms of the displacement functions is conducted to obtain the optimum solutions. The nondimensional frequency parameters $\Omega$ of multispan beam with different truncation are displayed in Figure 5 . The results converge rapidly with the number of truncations of the Jacobi polynomial increasing, which is consistent with the pattern of the number of segments, and the results are stable when the truncation terms $M$ reaches 4 . If the truncation terms $M$ is large, it will not only lead to an increase in computation, but also make the matrix pathological, so the polynomial truncation number is taken as 8 in this paper.

As stated previously, the Jacobi polynomial can be transformed into Legendre polynomials or Chebyshev polynomials by setting the values of two Jacobi parameters. Figure 6 demonstrates the relative percentage error of multispan beam with different Jacobi parameters, in which $\alpha=\beta=0.5$ is selected as reference value. It is apparently that 
TABLE 1: The spring stiffness values of the general edge conditions.

\begin{tabular}{lcc}
\hline Boundary conditions & Transverse constraint spring $k(\mathrm{~N} / \mathrm{m})$ & Rotation constraint spring $K(\mathrm{Nm} / \mathrm{rad})$ \\
\hline F & 0 & 0 \\
S & 0 & $10^{11}$ \\
P & $10^{11}$ & 0 \\
C & $10^{11}$ & $10^{11}$ \\
\hline
\end{tabular}

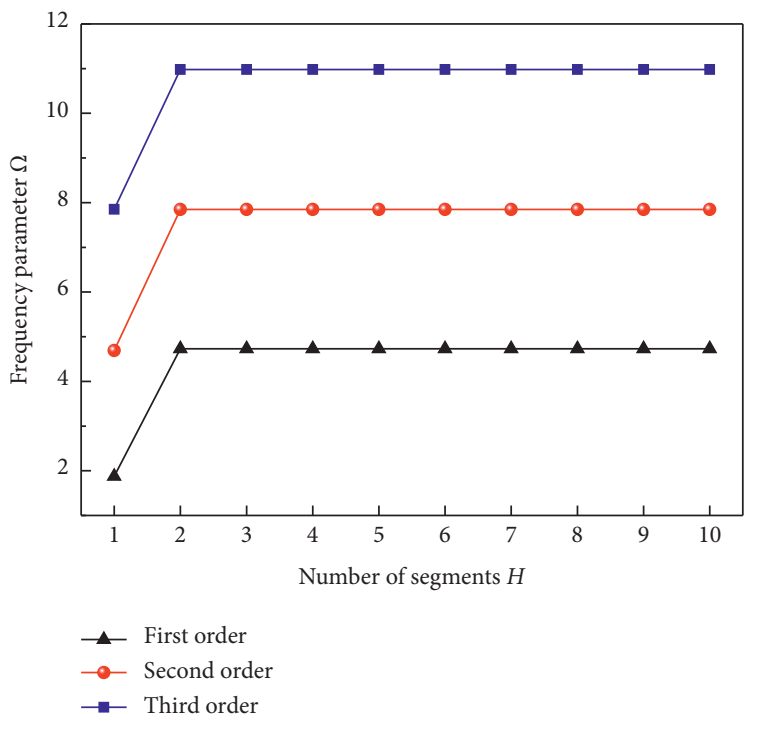

(a)

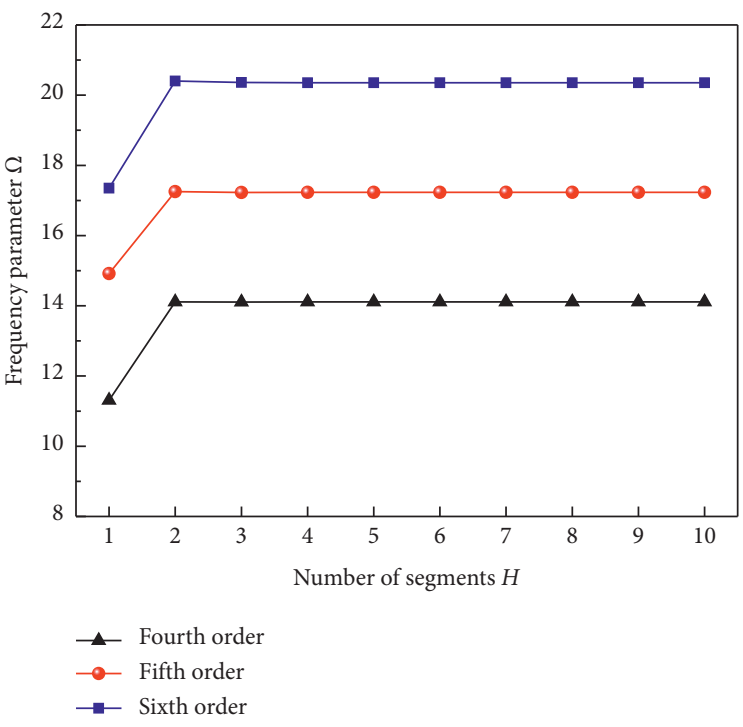

(b)

FIGURE 4: Frequency parameters $\Omega$ of multispan beam with different number of segments.

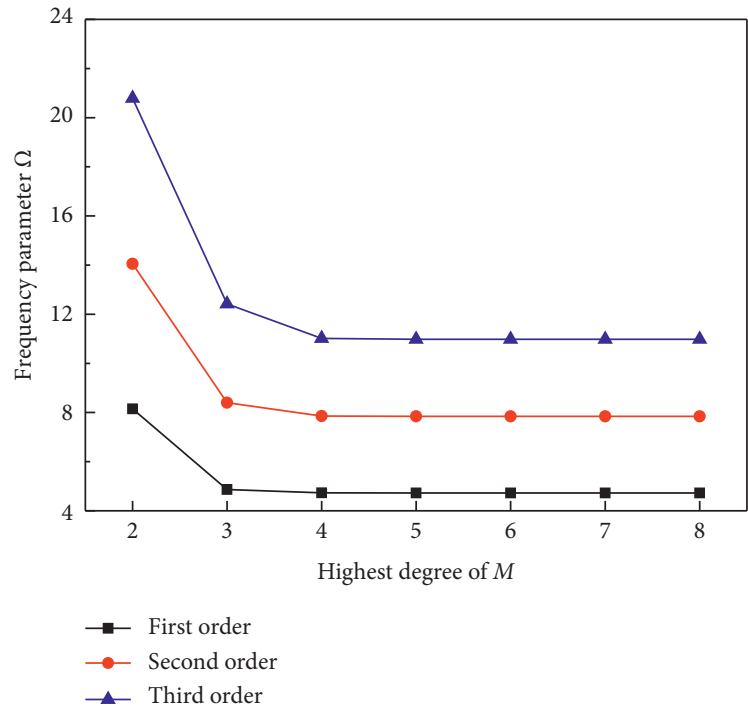

(a)

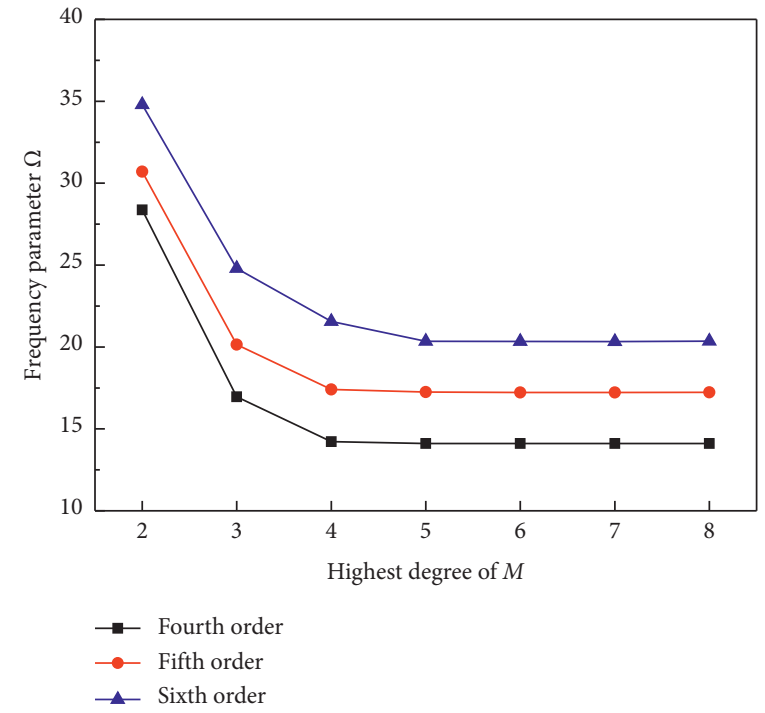

(b)

FIGURE 5: Frequency parameters $\Omega$ of multispan beam with different truncation.

the maximum relative percentage error is not more than $0.03 \%$ regardless of the value of $\alpha$ and $\beta$ in the current methodology, and the problem can be solved by any of the orthogonal polynomials in Jacobi systems, which means that the choice of polynomial can be various.
3.2. Free Vibration Behavior of a Multispan Beam. Firstly, the reliability and accuracy of the present approach is studied in this section. For this purpose, free vibration solutions of multispan beam under general boundary restraints are compared with those from the FEM and literature. Table 2 


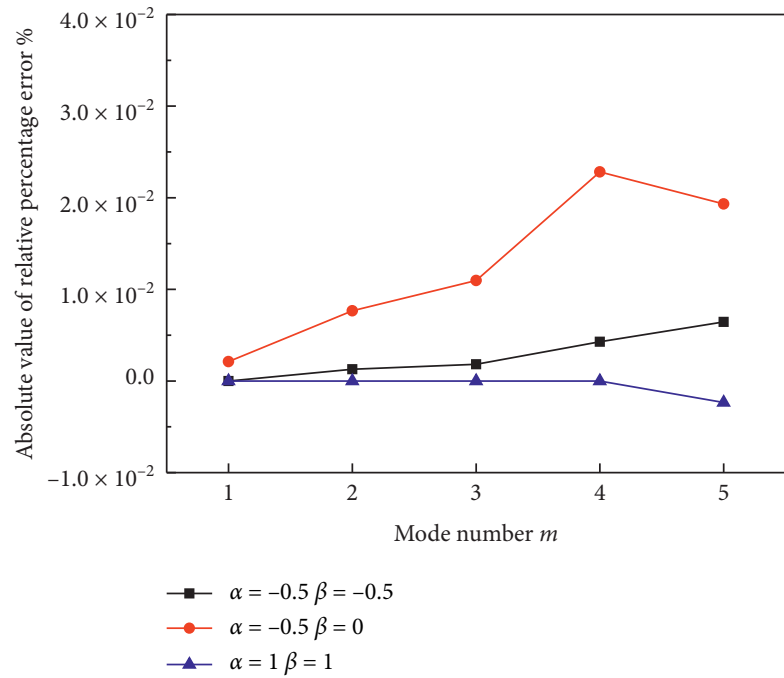

(a)

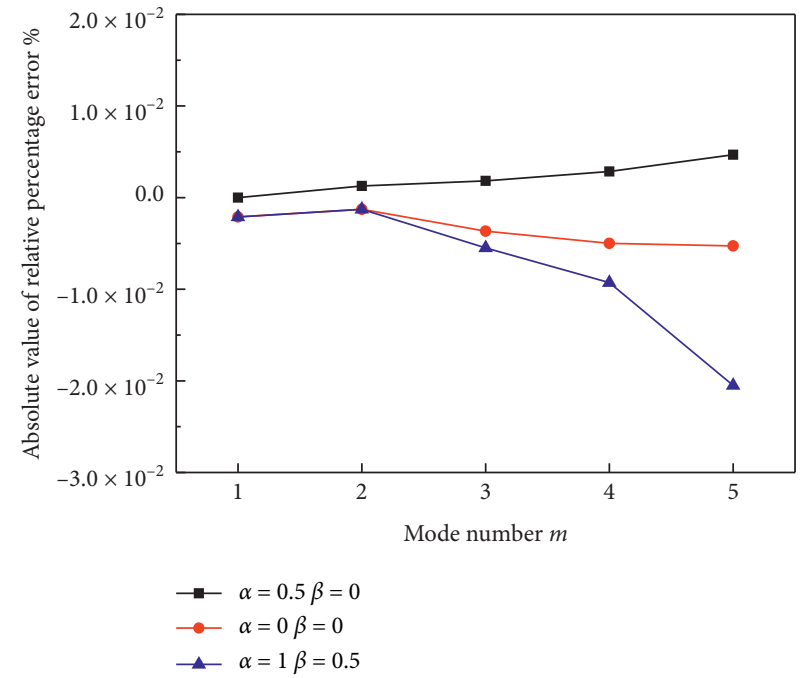

(b)

FIGURE 6: Relative percentage error of multispan beam with different Jacobi parameters.

TABLE 2: Comparison of frequency for multispan beam with different boundary condition $\left(k_{t}=10^{11} \mathrm{~N} / \mathrm{m}\right)$.

\begin{tabular}{|c|c|c|c|c|c|c|c|}
\hline \multirow{2}{*}{ Boundary conditions } & \multirow[b]{2}{*}{ Mode no. } & \multicolumn{2}{|c|}{ Single-span } & \multicolumn{2}{|c|}{ Two-span } & \multicolumn{2}{|c|}{ Four-span } \\
\hline & & FEM & Present & FEM & Present & FEM & Present \\
\hline & 1 & 106.38 & 106.38 & 292.21 & 292.21 & 864.87 & 864.88 \\
\hline $\mathrm{C}-\mathrm{C}$ & 2 & 292.21 & 292.21 & 422.12 & 422.17 & 1147.60 & 1148.26 \\
\hline$h=0.02$ & 3 & 570.15 & 570.17 & 936.88 & 936.97 & 1467.60 & 1469.73 \\
\hline \multirow[t]{3}{*}{$b=0.04$} & 4 & 936.88 & 936.97 & 1147.60 & 1148.30 & 1636.60 & 1640.14 \\
\hline & 5 & 1389.60 & 1389.85 & 1924.90 & 1925.77 & 3111.90 & 3120.22 \\
\hline & 1 & 47.03 & 47.02 & 47.03 & 47.02 & 292.21 & 292.21 \\
\hline S-S & 2 & 187.73 & 187.72 & 106.38 & 106.38 & 311.43 & 311.46 \\
\hline$h=0.02$ & 3 & 421.00 & 420.95 & 421.00 & 420.95 & 936.80 & 936.92 \\
\hline \multirow[t]{2}{*}{$b=0.08$} & 4 & 745.05 & 744.91 & 570.12 & 570.14 & 1308.10 & 1309.00 \\
\hline & 5 & 1157.40 & 1157.08 & 1157.40 & 1157.08 & 1924.60 & 1925.44 \\
\hline
\end{tabular}

and Figure 7, respectively, exhibit the comparison of frequency and predicted mode shapes for multispan beam. It can be easily to find that the results of current approach are in great agreement with those obtained by FEM. The comparison of the nondimensional frequency parameters with published literature $[44,48]$ in different boundary condition is displayed in Table 3 . It is clear that the present approach has great accuracy on the grounds of the comparison with FEM and published literature; we can get the conclusion that the present method has accurate precision to obtain the free vibration solutions of multispan beam.

Next, the influence of transverse constraint spring and rotation constraint spring on the vibration characteristics of multispan beam is discussed; the three-dimensional comparison graph of nondimensional frequency parameters $\Omega$ is shown in Figure 8. The multispan beam is fixed at one end and the transverse constraint spring and rotation constraint spring are, respectively, changed at the other end, from which the influence of both on the vibration characteristics of the multispan beam can be easily judged. The curvature of the graph does not change very much when transverse constraint spring is kept constant and rotation constraint spring is gradually increasing; on the contrary, the curvature of the graph changes a lot when rotation constraint spring is kept constant and transverse constraint spring is gradually increasing. Therefore, it can be clear to find that the effect of the transverse constraint spring on the vibration characteristics of the structure is greater than that of the rotation constraint spring; in other words, the transverse constraint spring limits the displacement of the structure and has a greater effect on the stiffness of the structure.

Table 4 and Figure 9 present the nondimensional frequency parameters of multispan beam with different number of modes under various boundary conditions. It is apparent to see that the boundary restraints have an obvious effect on the vibration behaviors of multispan beam; the nondimensional frequency parameters gradually increase as the boundary condition is enhanced. In addition, the effect of the shear correction factor on the vibration characteristics of the multispan beam structure is also investigated. It is not hard to find that there is a slight tendency for the frequency parameter to increase with the shear correction factor increase; however, the effect is not significant. Figure 10 displays the frequency parameters $\Omega$ of multispan beam 
FEM
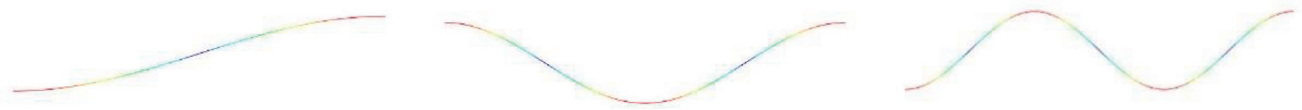

S-S

Single-

span

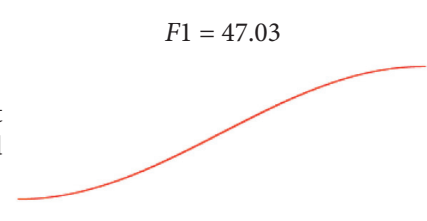

$F 1=47.02$

FEM

C-C

Two-

span

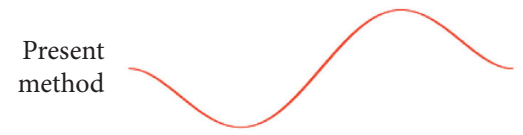

$F 1=292.21$
$F 2=187.73$

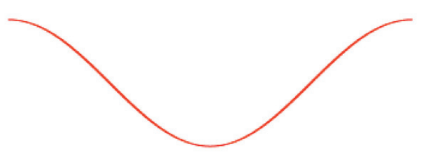

$F 2=187.71$

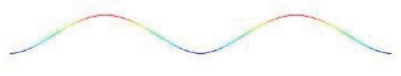

$F 2=422.12$

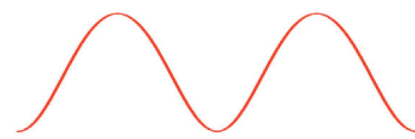

$F 2=422.17$

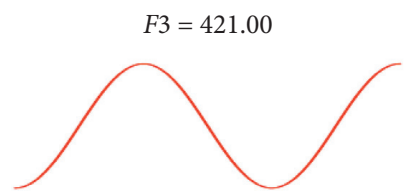

$F 3=420.95$

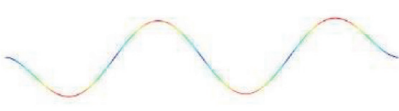

$F 3=936.88$

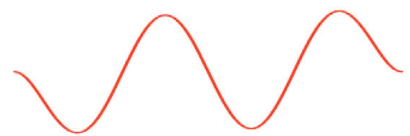

$F 3=936.97$

Figure 7: Comparison of the FEM and present method of predicted mode shapes for multispan beam.

TABLE 3: Comparison of the nondimensional frequency parameters with different boundary condition.

\begin{tabular}{lcccccccccc}
\hline \multirow{2}{*}{ Boundary conditions } & & \multicolumn{3}{c}{$h / L=0.02$} & \multicolumn{3}{c}{$h / L=0.05$} & & \multicolumn{3}{c}{$h / L=0.1$} \\
& Mode no. & Present & Ref [44] & Ref [48] & Present & Ref [44] & Ref [48] & Present & Ref [44] & Ref [48] \\
\hline & 1 & 4.7236 & 4.7236 & 4.7235 & 4.6899 & 4.6904 & 4.6899 & 4.5777 & 4.5813 & 4.5796 \\
& 2 & 7.8285 & 7.8285 & 7.8281 & 7.7042 & 7.7052 & 7.7035 & 7.3274 & 7.3365 & 7.3312 \\
C-C & 3 & 10.9352 & 10.9340 & 10.9340 & 10.6430 & 10.6430 & 10.6400 & 9.8530 & 9.8662 & 9.8561 \\
& 4 & 14.0173 & 14.0160 & 14.0150 & 13.4624 & 13.4670 & 13.4610 & 12.1196 & 12.1610 & 12.1450 \\
& 5 & 17.0718 & 17.0700 & 17.0680 & 16.1648 & 16.1690 & 16.1590 & 14.2114 & 14.2540 & 14.2320 \\
& 6 & 20.0941 & 20.0900 & 20.0870 & 18.7432 & 18.7460 & 18.7320 & 16.1259 & 16.1760 & 16.1490 \\
\hline & 1 & 3.1405 & 3.1405 & 3.1405 & 3.1349 & 3.1351 & 3.1349 & 3.1150 & 3.1159 & 3.1157 \\
& 2 & 6.2747 & 6.2748 & 6.2747 & 6.2307 & 6.2319 & 6.2314 & 6.0862 & 6.0925 & 6.0907 \\
P-P & 3 & 9.3962 & 9.3966 & 9.3963 & 9.2534 & 9.2570 & 9.2554 & 8.8282 & 8.8456 & 8.8405 \\
& 4 & 12.4989 & 12.5000 & 12.4990 & 12.1741 & 12.1840 & 12.1810 & 11.3043 & 11.3520 & 11.3430 \\
& 5 & 15.5779 & 15.5790 & 15.5780 & 14.9849 & 14.9990 & 14.9930 & 13.5763 & 13.6280 & 13.6130 \\
& 6 & 18.6282 & 18.6300 & 18.6280 & 17.6688 & 17.6910 & 17.6810 & 15.6270 & 15.7000 & 15.6790 \\
\hline
\end{tabular}

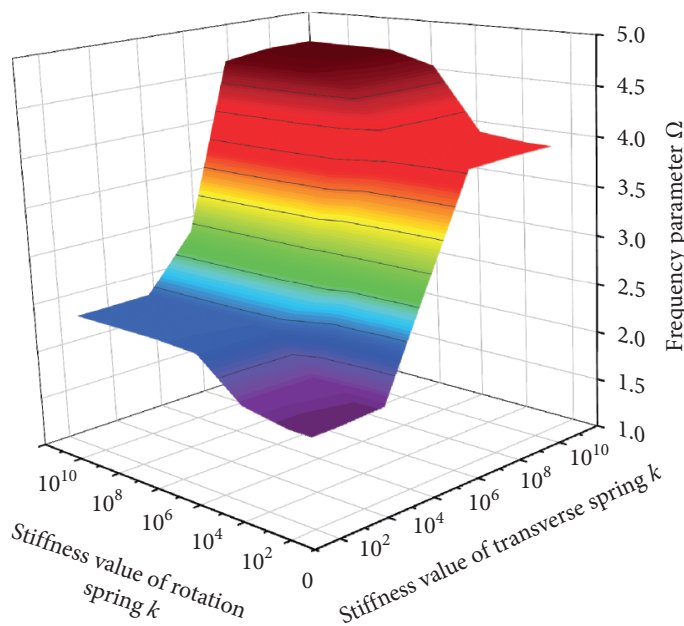

(a)

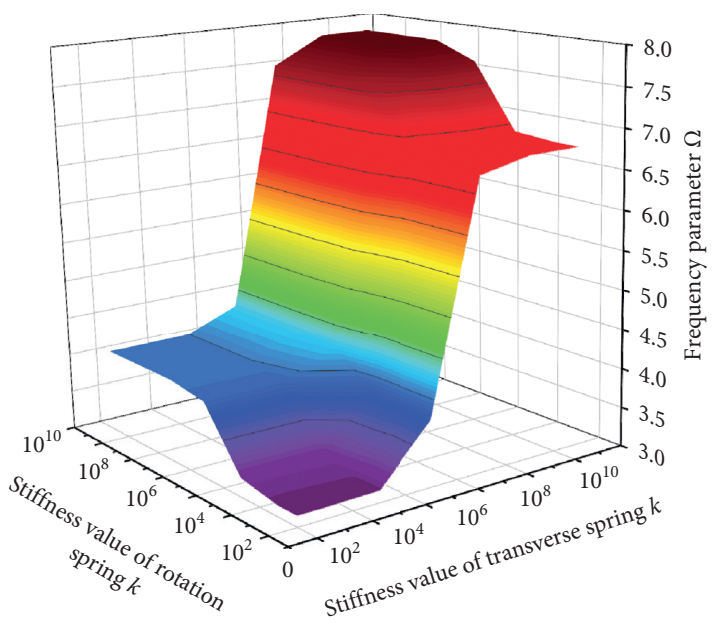

(b)

FIGURE 8: Comparison of frequency parameters $\Omega$ with transverse constraint spring and rotation constraint spring. 
TABLE 4: Nondimensional frequency parameters of single-span beam with different number of modes under general boundary conditions.

\begin{tabular}{|c|c|c|c|c|c|c|}
\hline & Mode no. & $\mathrm{FC}$ & PC & $\mathrm{PP}$ & $\mathrm{CC}$ & CS \\
\hline \multirow{6}{*}{$\kappa=4 / 6$} & 1 & 1.8747 & 3.9228 & 3.1403 & 4.7221 & 2.364 \\
\hline & 2 & 4.6880 & 7.05 & 6.2731 & 7.8232 & 5.4884 \\
\hline & 3 & 7.8304 & 10.1587 & 9.3908 & 10.9228 & 8.6071 \\
\hline & 4 & 10.9332 & 13.2424 & 12.4864 & 13.9936 & 11.7043 \\
\hline & 5 & 14.0103 & 16.2955 & 15.554 & 17.0315 & 14.7733 \\
\hline & 6 & 17.0555 & 19.3119 & 18.5878 & 20.0302 & 17.8088 \\
\hline \multirow{6}{*}{$\kappa=5 / 6$} & 1 & 1.8748 & 3.9235 & 3.1405 & 4.7236 & 2.3642 \\
\hline & 2 & 4.6889 & 7.0532 & 6.2747 & 7.8285 & 5.4901 \\
\hline & 3 & 7.8342 & 10.1673 & 9.3962 & 10.9352 & 8.6125 \\
\hline & 4 & 10.9429 & 13.2601 & 12.4989 & 14.0173 & 11.7169 \\
\hline & 5 & 14.0298 & 16.327 & 15.5779 & 17.0718 & 14.7973 \\
\hline & 6 & 17.0896 & 19.3623 & 18.6282 & 20.0941 & 17.8495 \\
\hline \multirow{6}{*}{$\kappa=1$} & 1 & 1.8748 & 3.9239 & 3.1407 & 4.7246 & 2.3643 \\
\hline & 2 & 4.6896 & 7.0553 & 6.2757 & 7.8321 & 5.4912 \\
\hline & 3 & 7.8368 & 10.173 & 9.3997 & 10.9436 & 8.6161 \\
\hline & 4 & 10.9494 & 13.2721 & 12.5072 & 14.0335 & 11.7254 \\
\hline & 5 & 14.0429 & 16.3484 & 15.5938 & 17.0989 & 14.8134 \\
\hline & 6 & 17.1125 & 19.3978 & 18.6553 & 20.1357 & 17.8764 \\
\hline \multirow{6}{*}{$\kappa=7 / 6$} & 1 & 1.8749 & 3.9243 & 3.1408 & 4.7253 & 2.3644 \\
\hline & 2 & 4.6900 & 7.0568 & 6.2765 & 7.8347 & 5.4919 \\
\hline & 3 & 7.8386 & 10.1771 & 9.4023 & 10.9497 & 8.6188 \\
\hline & 4 & 10.9542 & 13.2808 & 12.5132 & 14.0454 & 11.7315 \\
\hline & 5 & 14.0285 & 16.364 & 15.6055 & 17.119 & 14.8253 \\
\hline & 6 & 17.1541 & 19.423 & 18.6766 & 20.1678 & 17.8963 \\
\hline
\end{tabular}

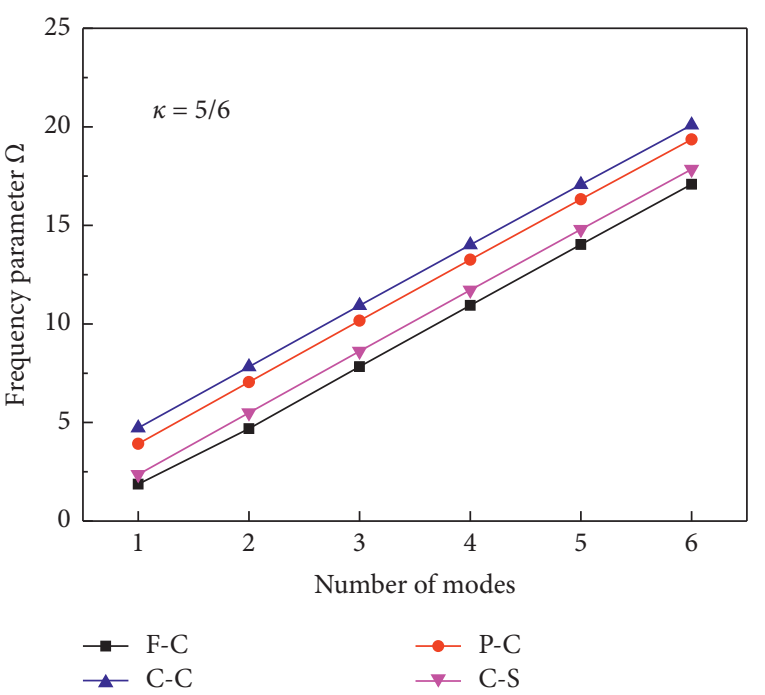

(a)

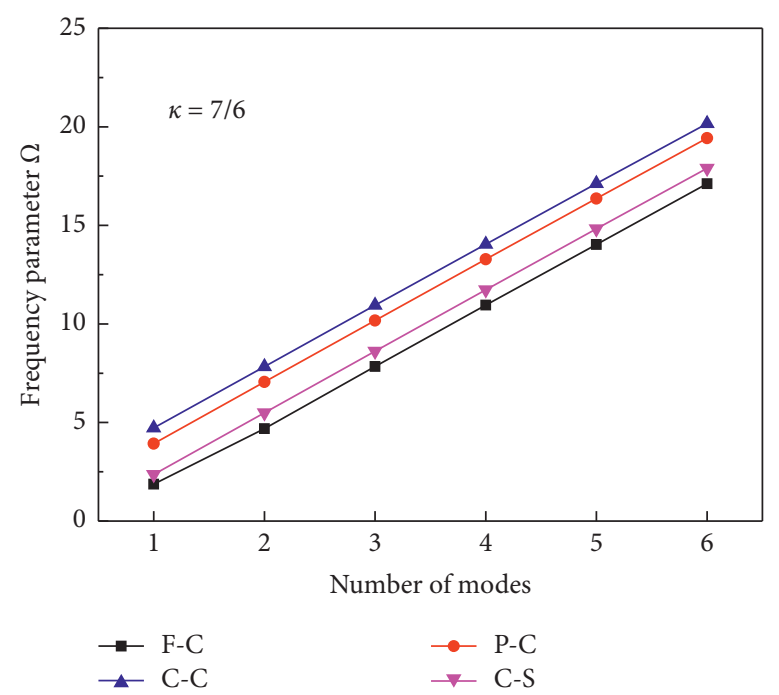

(b)

FIGURE 9: Frequency parameters $\Omega$ of multispan beam with different number of modes under various boundary conditions.

with different number of modes under various shear correction factors; as shown in Figure 10, the frequency parameters barely change with the increase of shear correction factor, and only a slight increasing trend can be seen.

As shown in Table $3, h / L$ ratio seems to have little effect on the nondimensional frequency. Therefore, the natural frequency of single-span beam under general boundary restraints with different $h / L$ ratio is shown in Table 5 and Figure 11, where five different kinds of $h / L$ are included. The consequence can be drawn that the natural frequency increases significantly with the increase of $h / L$ ratio; that is, the increase of the thickness of the structure increases the structural stiffness to a greater extent.

Tables 6 and 7 and Figures 12 and 13, respectively, display the nondimensional frequency parameters of multispan beam subject to general boundary conditions with different numbers and stiffness of supporting springs. Unsurprisingly, we can clearly get that the nondimensional frequency parameters gradually increase with the numbers and stiffness of supporting springs increasing. That is to say, 


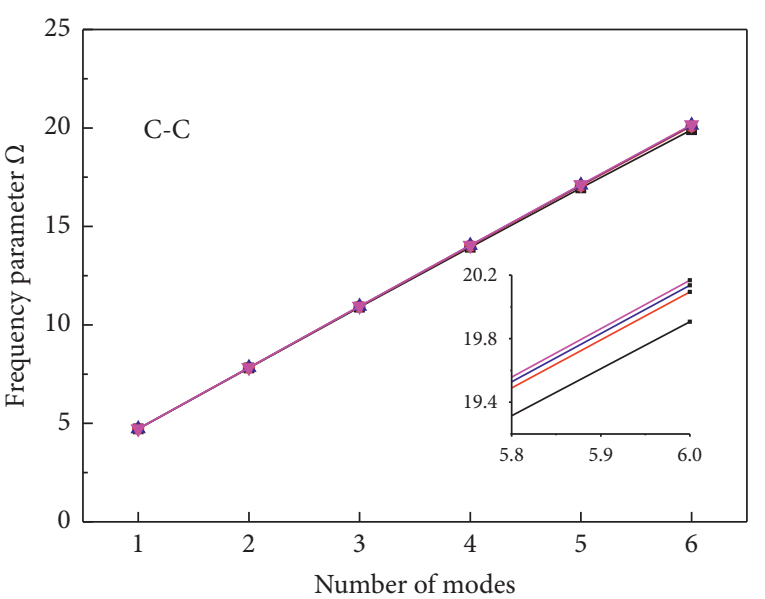

$\rightarrow \kappa=4 / 6$

$\triangle \kappa=1$ $\rightarrow \kappa=5 / 6$

$\rightarrow \kappa=7 / 6$

(a)

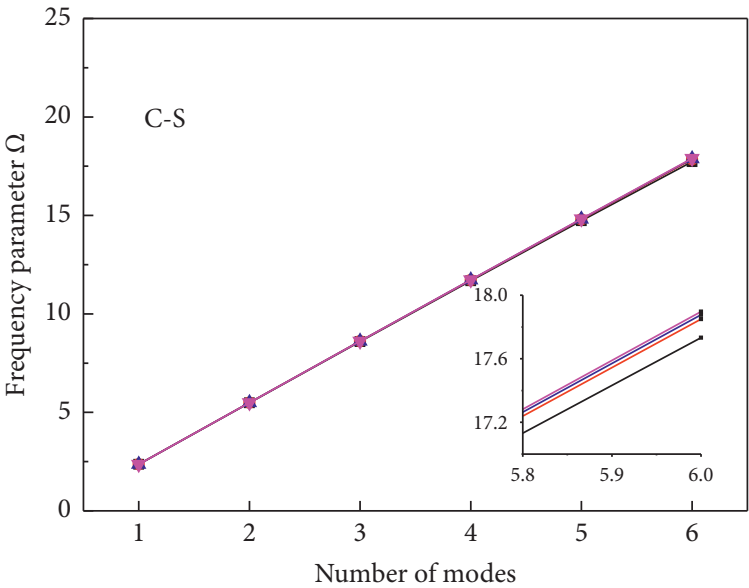

$\rightarrow \kappa=4 / 6$

$\neg \kappa=1$ $\rightarrow \kappa=5 / 6$

$\neg \kappa=7 / 6$

(b)

FIgURE 10: Frequency parameters $\Omega$ of multispan beam with different number of modes under various shear correction factor.

TABLe 5: Natural frequency of single-span beam subject to general boundary conditions with different $h / L$ ratios.

\begin{tabular}{|c|c|c|c|c|c|c|}
\hline \multirow{2}{*}{ Boundary conditions } & \multirow[t]{2}{*}{$h / L$} & \multicolumn{5}{|c|}{ Mode no. } \\
\hline & & 1 & 2 & 3 & 4 & 5 \\
\hline \multirow{5}{*}{ F-C } & 0.01 & 8.38 & 52.50 & 146.89 & 287.53 & 474.63 \\
\hline & 0.02 & 16.76 & 104.83 & 292.63 & 570.96 & 938.57 \\
\hline & 0.03 & 25.13 & 156.82 & 436.23 & 846.86 & 1383.26 \\
\hline & 0.04 & 33.48 & 208.28 & 576.37 & 1110.92 & 1798.82 \\
\hline & 0.05 & 41.83 & 259.09 & 712.53 & 1362.06 & 2184.14 \\
\hline \multirow{5}{*}{$\mathrm{P}-\mathrm{C}$} & 0.01 & 36.74 & 118.98 & 248.00 & 423.52 & 645.19 \\
\hline & 0.02 & 73.39 & 237.19 & 492.89 & 838.41 & 1271.13 \\
\hline & 0.03 & 109.88 & 353.94 & 732.04 & 1237.71 & 1863.04 \\
\hline & 0.04 & 146.09 & 468.33 & 962.11 & 1613.08 & 2405.39 \\
\hline & 0.05 & 181.97 & 579.98 & 1182.11 & 1963.32 & 2898.18 \\
\hline \multirow{5}{*}{ P-P } & 0.01 & 23.52 & 94.05 & 211.43 & 375.44 & 585.75 \\
\hline & 0.02 & 47.02 & 187.72 & 420.95 & 744.88 & 1157.42 \\
\hline & 0.03 & 70.48 & 280.63 & 626.73 & 1102.85 & 1701.73 \\
\hline & 0.04 & 93.86 & 372.43 & 827.15 & 1444.85 & 2210.23 \\
\hline & 0.05 & 117.14 & 462.79 & 1020.84 & 1767.64 & 2677.90 \\
\hline \multirow{5}{*}{$\mathrm{C}-\mathrm{C}$} & 0.01 & 53.30 & 146.79 & 287.43 & 474.43 & 707.46 \\
\hline & 0.02 & 106.38 & 292.21 & 570.17 & 936.97 & 1389.85 \\
\hline & 0.03 & 159.05 & 435.09 & 844.45 & 1378.74 & 2029.52 \\
\hline & 0.04 & 211.04 & 573.77 & 1104.97 & 1787.17 & 2604.57 \\
\hline & 0.05 & 262.23 & 707.81 & 1351.21 & 2163.57 & 3120.54 \\
\hline \multirow{5}{*}{ C-S } & 0.01 & 13.33 & 72.01 & 177.66 & 329.96 & 528.66 \\
\hline & 0.02 & 26.65 & 143.71 & 353.66 & 654.58 & 1044.07 \\
\hline & 0.03 & 39.94 & 214.82 & 526.52 & 969.26 & 1535.79 \\
\hline & 0.04 & 53.19 & 285.03 & 694.60 & 1269.10 & 1992.79 \\
\hline & 0.05 & 66.38 & 354.11 & 856.97 & 1552.28 & 2413.41 \\
\hline
\end{tabular}

the increase in the numbers and stiffness of supporting springs leads to an increase in the stiffness of the multispan beam structure.

3.3. Forced Vibration Behavior of a Multispan Beam. The multispan beam may be subjected to external excitation loads in engineering applications, and this section conducted forced vibration analysis for the multispan beam. The excitation load is a unit concentrated force in the downward direction, located at the middle of the beam, the analysis frequency band is $2-1000 \mathrm{~Hz}$ with the interval being $2 \mathrm{~Hz}$.

In order to verify the accuracy of current methodology for forced vibration of multispan beam, the comparison of the FEM and present approach of forced 


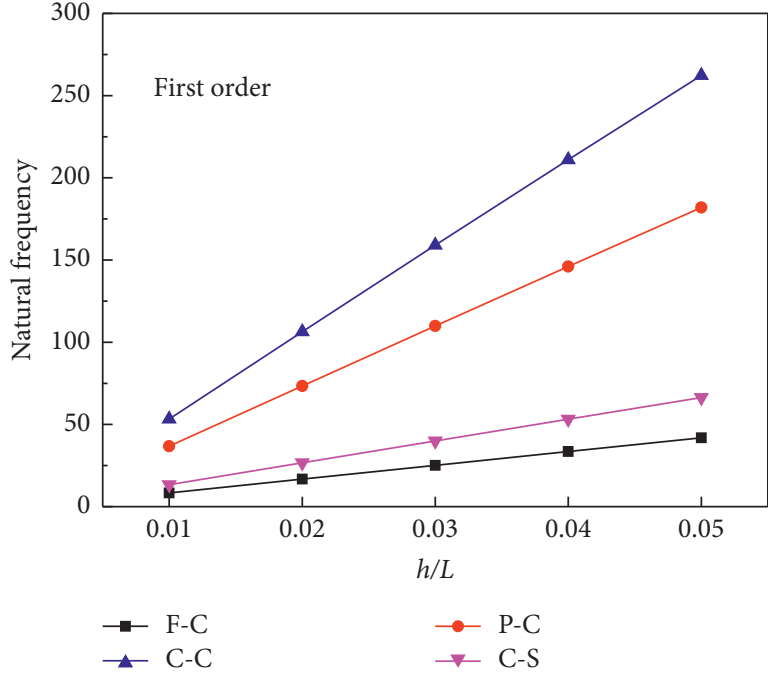

(a)

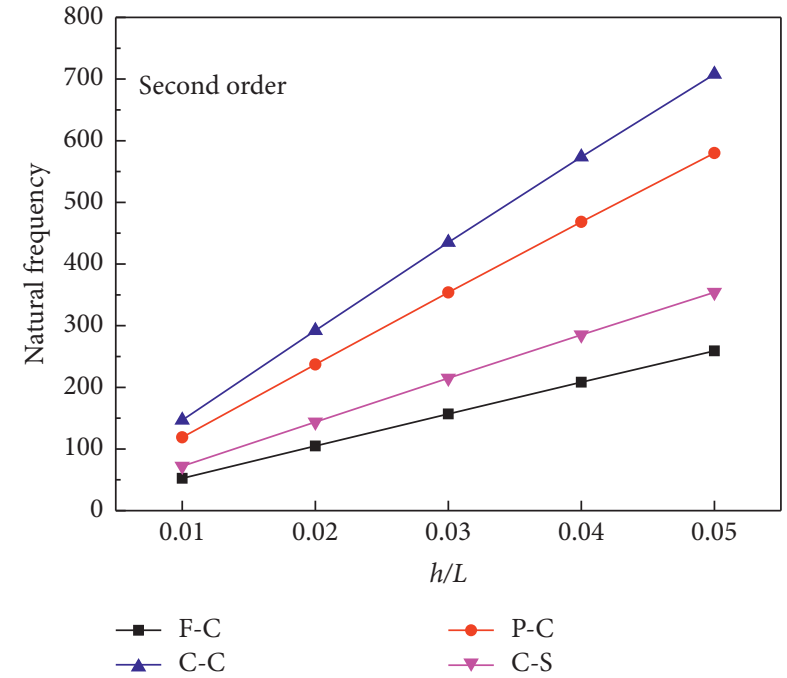

(b)

FIGURE 11: Frequency parameters $\Omega$ of single-span beam with different $h / L$ ratios.

TABLE 6: Nondimensional frequency parameters of multispan beam subject to general boundary conditions with different numbers of supporting springs.

\begin{tabular}{|c|c|c|c|c|c|c|}
\hline \multirow{2}{*}{ Boundary conditions } & \multirow{2}{*}{ Number of supporting springs } & \multicolumn{5}{|c|}{ Mode no. } \\
\hline & & 1 & 2 & 3 & 4 & 5 \\
\hline \multirow{5}{*}{ F-C } & 0 & 1.8748 & 4.6889 & 7.8342 & 10.9429 & 14.0298 \\
\hline & 1 & 3.1390 & 7.8330 & 9.3792 & 14.0303 & 15.5353 \\
\hline & 2 & 4.6184 & 10.6594 & 12.7664 & 14.0642 & 19.8544 \\
\hline & 3 & 6.1401 & 13.5133 & 15.5344 & 17.5290 & 18.5285 \\
\hline & 4 & 7.6686 & 16.4144 & 18.3171 & 20.4367 & 22.2501 \\
\hline \multirow{5}{*}{$\mathrm{P}-\mathrm{C}$} & 0 & 3.9235 & 7.0532 & 10.1673 & 13.2601 & 16.3270 \\
\hline & 1 & 6.7730 & 8.8871 & 13.0061 & 15.0232 & 19.1158 \\
\hline & 2 & 9.7470 & 11.7167 & 13.7094 & 18.9990 & 20.9373 \\
\hline & 3 & 12.7626 & 14.4393 & 16.5925 & 18.2721 & 24.9088 \\
\hline & 4 & 15.7912 & 17.2493 & 19.3532 & 21.4813 & 22.9936 \\
\hline \multirow{5}{*}{ P-P } & 0 & 3.1405 & 6.2747 & 9.3962 & 12.4989 & 15.5779 \\
\hline & 1 & 6.2747 & 7.8286 & 12.4991 & 14.0177 & 18.6297 \\
\hline & 2 & 9.3962 & 10.6206 & 12.8273 & 18.6279 & 19.8906 \\
\hline & 3 & 12.4991 & 13.4679 & 15.5182 & 17.5560 & 24.6486 \\
\hline & 4 & 15.5781 & 16.3927 & 18.2606 & 20.4574 & 22.4309 \\
\hline \multirow{5}{*}{$\mathrm{C}-\mathrm{C}$} & 0 & 4.7236 & 7.8285 & 10.9352 & 14.0173 & 17.0718 \\
\hline & 1 & 7.8287 & 9.4098 & 14.0185 & 15.5191 & 20.0975 \\
\hline & 2 & 10.6181 & 12.7926 & 14.0823 & 19.8445 & 21.8922 \\
\hline & 3 & 13.4684 & 15.5188 & 17.5573 & 18.5473 & 25.5818 \\
\hline & 4 & 16.3748 & 18.2761 & 20.4392 & 22.2724 & 23.2536 \\
\hline \multirow{5}{*}{ C-S } & 0 & 2.3642 & 5.4901 & 8.6125 & 11.7169 & 14.7973 \\
\hline & 1 & 4.0545 & 8.3659 & 10.4255 & 14.5283 & 16.5663 \\
\hline & 2 & 5.9861 & 10.9737 & 13.3968 & 15.4543 & 20.1807 \\
\hline & 3 & 7.9553 & 13.7077 & 15.9991 & 18.1054 & 20.3568 \\
\hline & 4 & 9.9302 & 16.5455 & 18.6778 & 20.9984 & 22.8912 \\
\hline
\end{tabular}

vibration response for multispan beam is shown in Figure 14. It is apparent to find that the current method agrees well with the FEM results; the curve trend of the two is basically the same, with only little deviation at the individual peak. That is to say, the present method can effectively analyze the forced vibration characteristics for multispan beam.
Having validated the correctness of the current method for forced vibration analysis of multispan beam, parametric investigations are conducted to analyze the steady-state vibration behaviors. Firstly, Figure 15 displays the comparison of the forced vibration response of multispan beam with different boundary conditions. The results reveal that the boundary conditions have a significant effect on the 
TABLE 7: Nondimensional frequency parameters of two-span beam subject to general boundary conditions with different stiffness of supporting springs.

\begin{tabular}{|c|c|c|c|c|c|c|}
\hline \multirow{2}{*}{ Boundary conditions } & \multirow{2}{*}{ Stiffness of supporting spring $(\mathrm{N} / \mathrm{m})$} & \multicolumn{5}{|c|}{ Mode no. } \\
\hline & & 1 & 2 & 3 & 4 & 5 \\
\hline \multirow{5}{*}{ F-C } & 0 & 1.8748 & 4.6889 & 7.8343 & 10.9431 & 14.0304 \\
\hline & $10^{2}$ & 1.8751 & 4.6890 & 7.8343 & 10.9431 & 14.0305 \\
\hline & $10^{5}$ & 2.1139 & 4.7758 & 7.8343 & 10.9499 & 14.0305 \\
\hline & $10^{8}$ & 3.1332 & 7.8328 & 9.1911 & 14.0302 & 14.5828 \\
\hline & $10^{11}$ & 3.1390 & 7.8330 & 9.3792 & 14.0303 & 15.5353 \\
\hline \multirow{5}{*}{$\mathrm{P}-\mathrm{C}$} & 0 & 3.9235 & 7.0533 & 10.1675 & 13.2607 & 16.3281 \\
\hline & $10^{2}$ & 3.9236 & 7.0533 & 10.1675 & 13.2608 & 16.3281 \\
\hline & $10^{5}$ & 4.0685 & 7.0574 & 10.1747 & 13.2613 & 16.3298 \\
\hline & $10^{8}$ & 6.7572 & 8.765 & 12.8592 & 14.366 & 18.2301 \\
\hline & $10^{11}$ & 6.773 & 8.8871 & 13.0061 & 15.0232 & 19.1158 \\
\hline \multirow{5}{*}{ P-P } & 0 & 3.1405 & 6.2747 & 9.3962 & 12.4991 & 15.5784 \\
\hline & $10^{2}$ & 3.1408 & 6.2747 & 9.3963 & 12.4991 & 15.5783 \\
\hline & $10^{5}$ & 3.3946 & 6.2747 & 9.407 & 12.4991 & 15.5798 \\
\hline & $10^{8}$ & 6.2747 & 7.7204 & 12.4991 & 13.3361 & 18.0186 \\
\hline & $10^{11}$ & 6.2747 & 7.8286 & 12.4991 & 14.0177 & 18.6297 \\
\hline \multirow{5}{*}{$\mathrm{C}-\mathrm{C}$} & 0 & 4.7236 & 7.8287 & 10.9356 & 14.0185 & 17.0735 \\
\hline & $10^{2}$ & 4.7237 & 7.8287 & 10.9356 & 14.0187 & 17.0736 \\
\hline & $10^{5}$ & 4.8265 & 7.8287 & 10.9423 & 14.0185 & 17.0753 \\
\hline & $10^{8}$ & 7.8287 & 9.2265 & 14.0185 & 14.5694 & 19.108 \\
\hline & $10^{11}$ & 7.8287 & 9.4098 & 14.0185 & 15.5191 & 20.0975 \\
\hline \multirow{5}{*}{ C-S } & 0 & 2.3642 & 5.4901 & 8.6126 & 11.7171 & 14.7979 \\
\hline & $10^{2}$ & 2.3645 & 5.4902 & 8.6126 & 11.7171 & 14.7981 \\
\hline & $10^{5}$ & 2.5757 & 5.5406 & 8.6146 & 11.7218 & 14.7984 \\
\hline & $10^{8}$ & 4.0427 & 8.3378 & 10.2199 & 14.2822 & 15.7002 \\
\hline & $10^{11}$ & 4.0545 & 8.3659 & 10.4255 & 14.5283 & 16.5663 \\
\hline
\end{tabular}

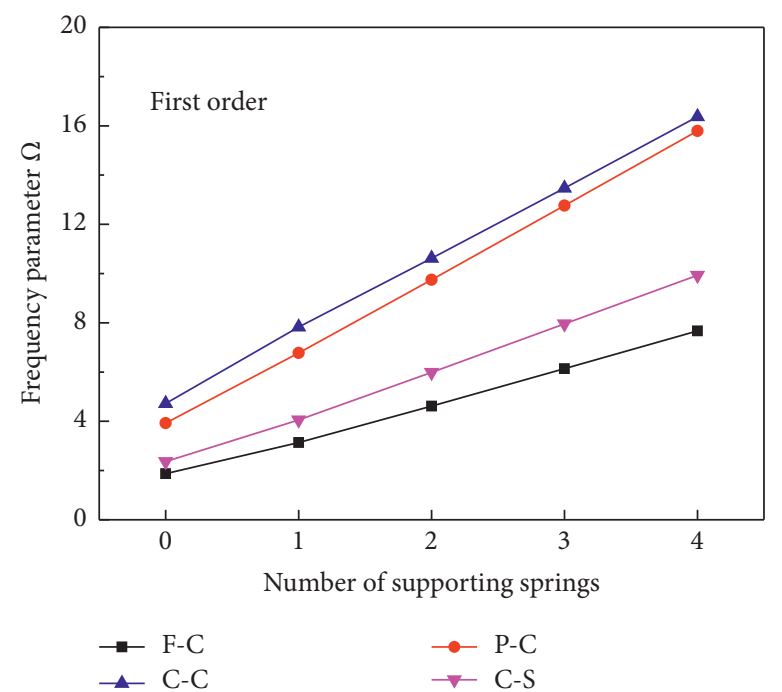

(a)

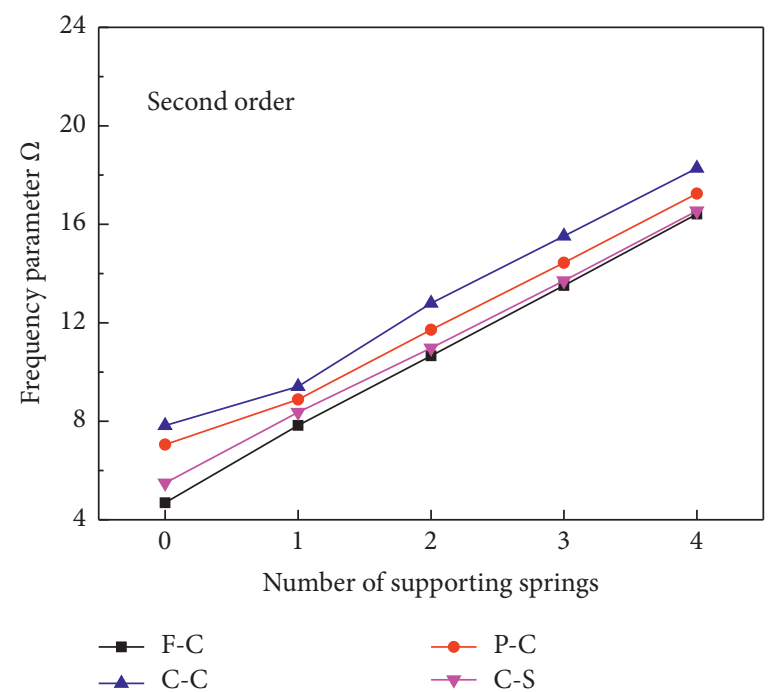

(b)

FIGURE 12: Frequency parameters $\Omega$ of multispan beam with different numbers of supporting springs.

structural forced vibration response; the first peak frequency of the structural forced response gradually increases with the enhancement of the boundary stiffness, while the number of peaks decreases. At the same time, it is not hard to find that the peak of the forced response corresponds to the natural frequency of the structure.
Next, the purpose of this section is to explore the influence of beam structural parameters on forced vibration. Figure 16 exhibits the comparison of the forced vibration response of multispan beam with different $h / L$ ratios. The results demonstrate that the stiffness increases and the natural frequency increases as the thickness of the structure 


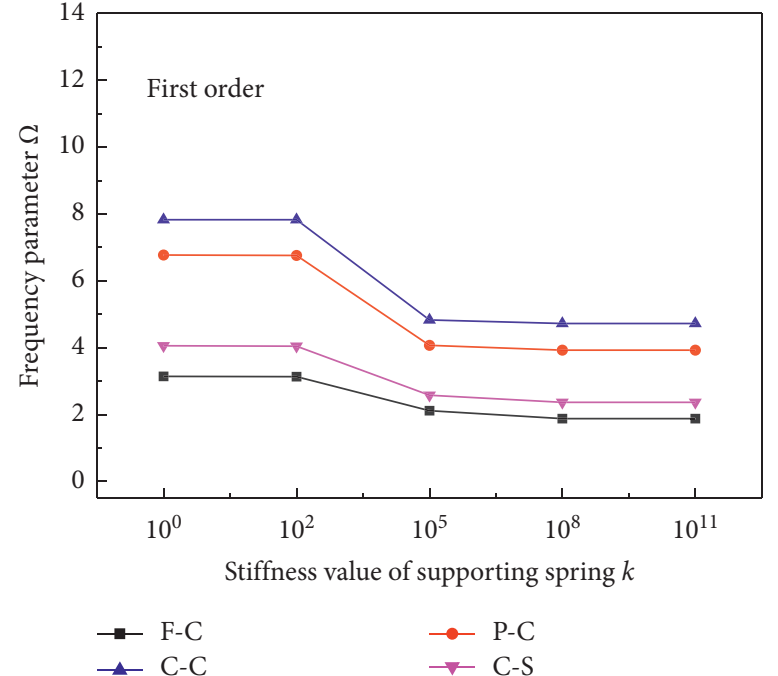

(a)

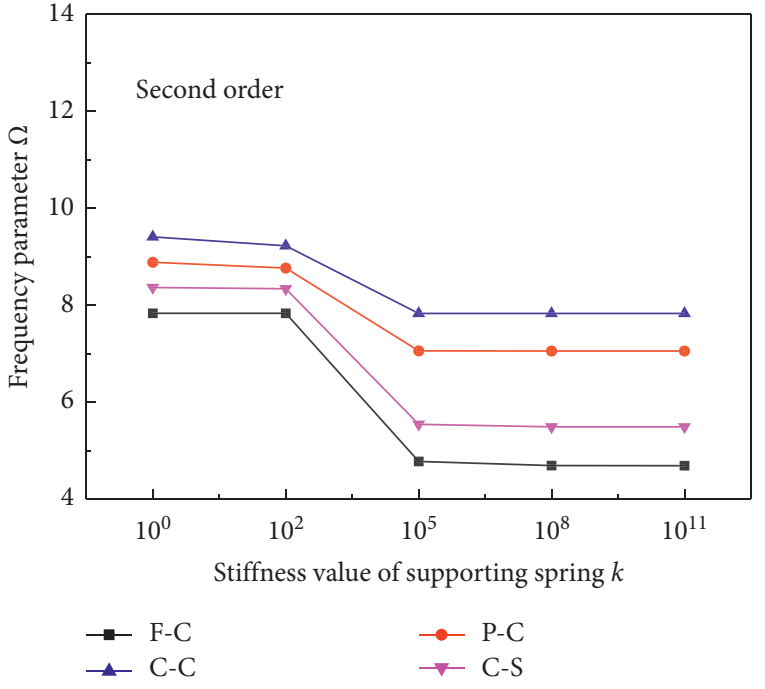

(b)

FIGURE 13: Frequency parameters $\Omega$ of two-span beam with different stiffness of supporting springs.
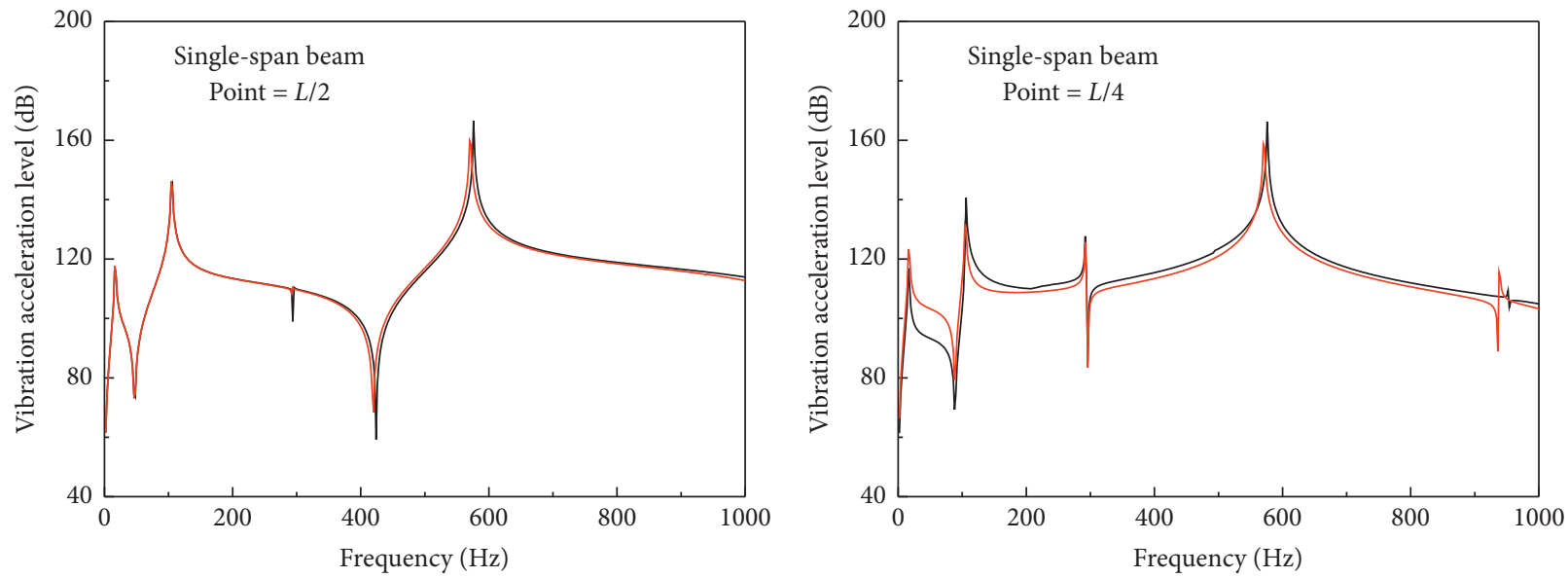

- Present method

— FEM

_ Present method

FEM

(a)

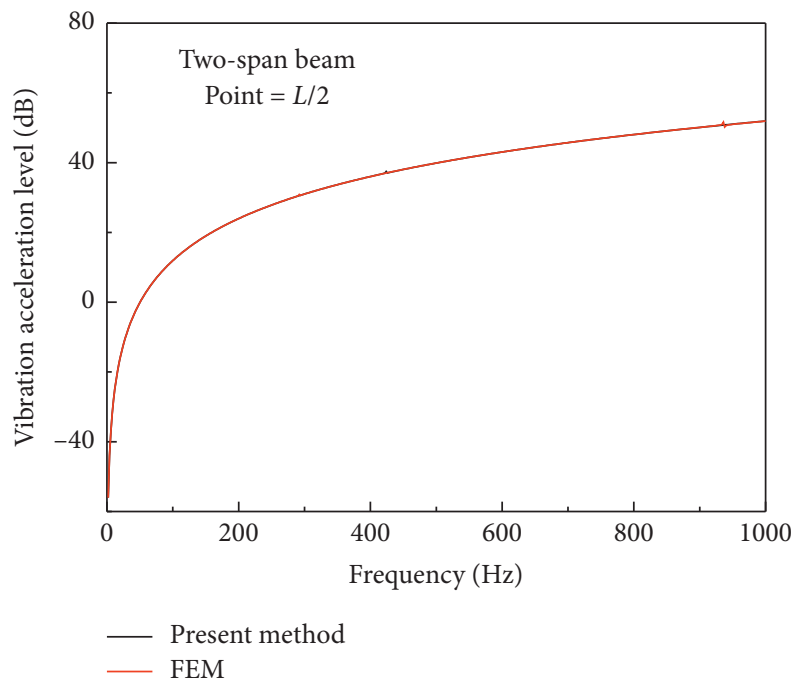

(c)

FIgURE 14: Comparison of the FEM and present method of forced vibration response for multispan beam. 

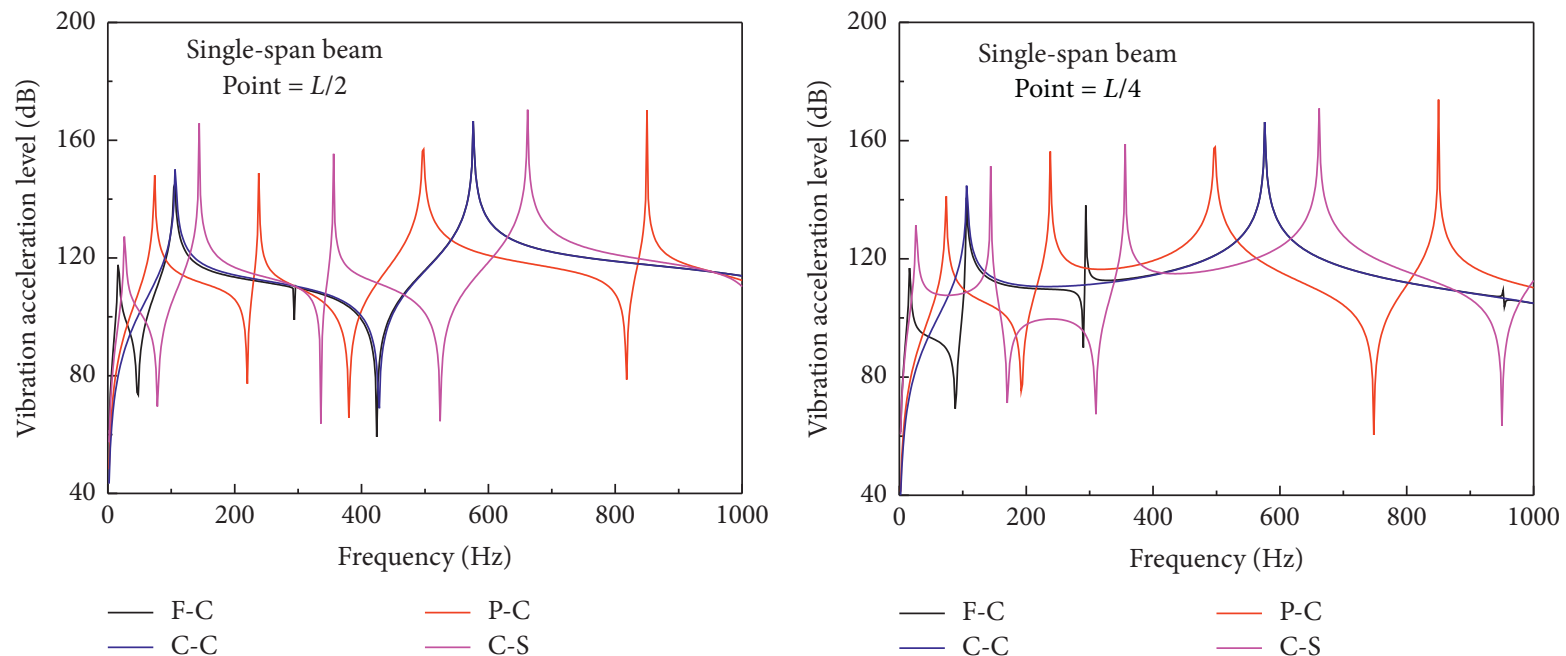

(a)
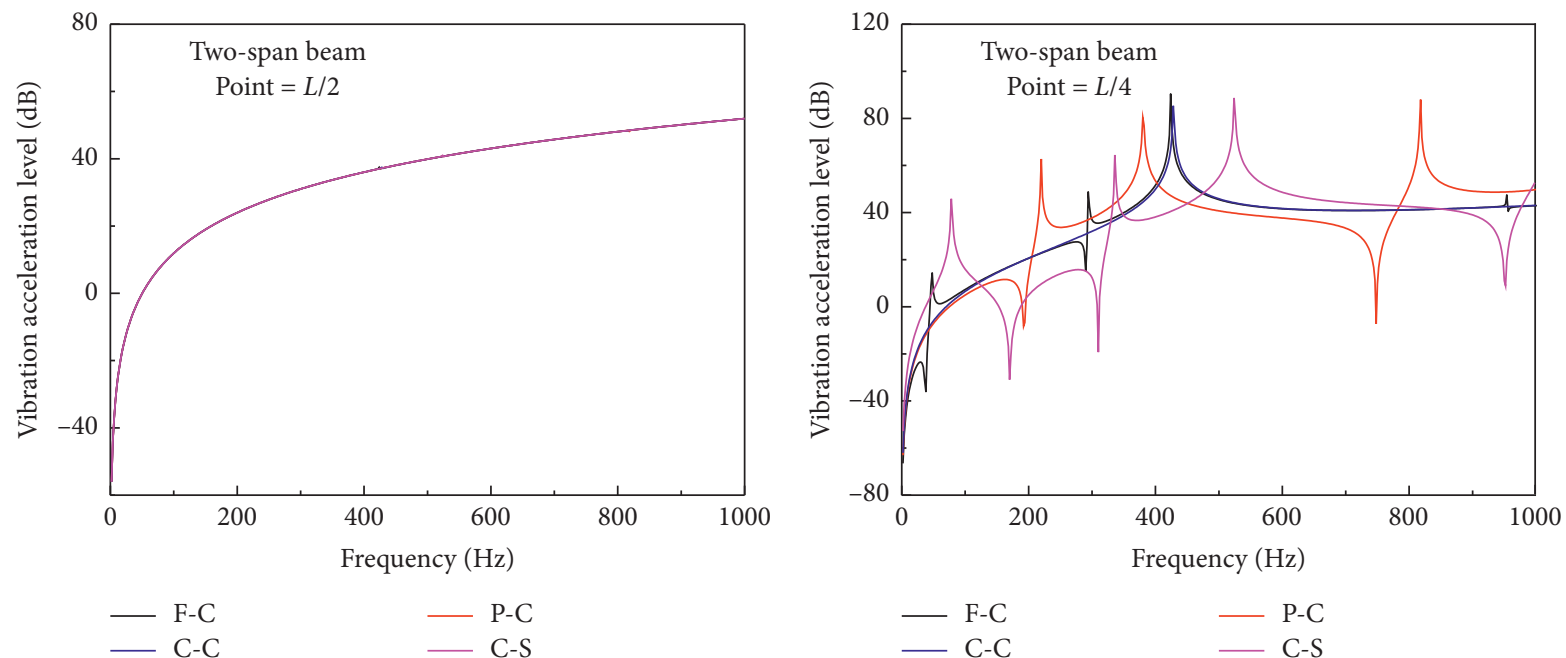

- F-C

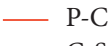

(c)

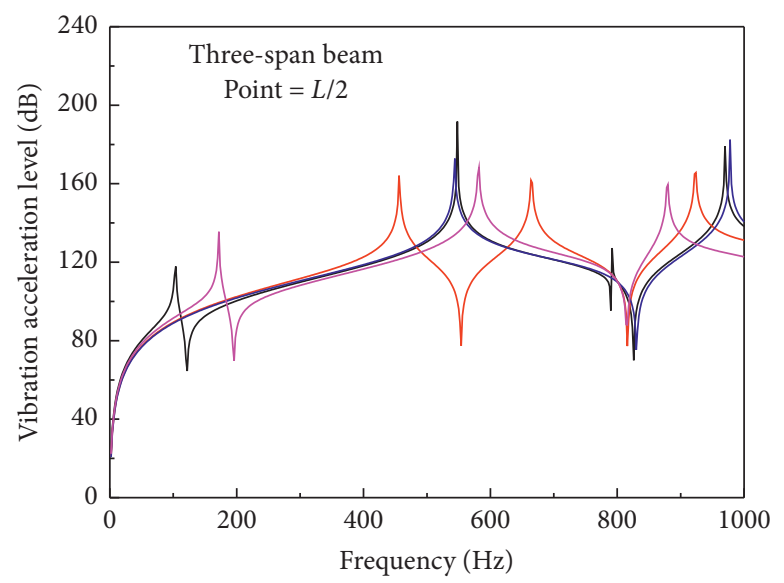

(d)

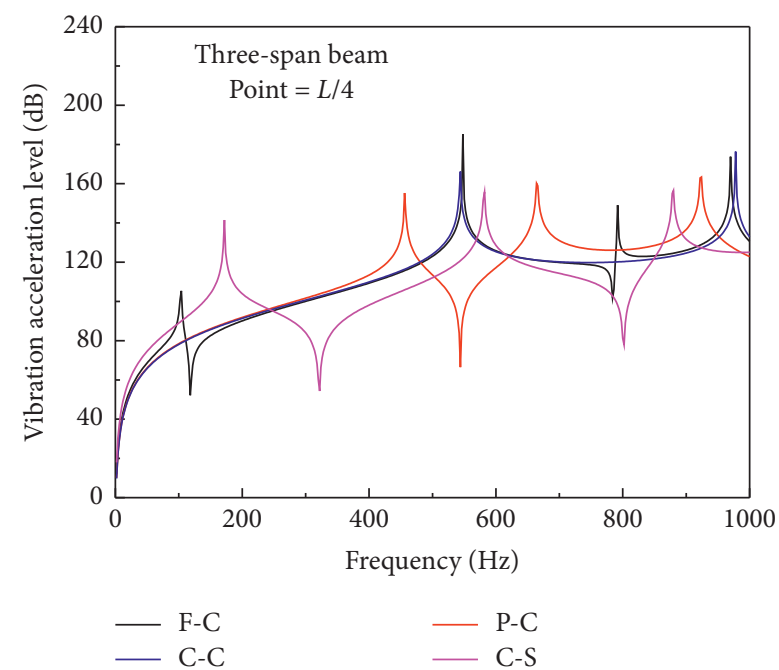

- F-C

- P-C

(e)

(f)

FIGURE 15: Comparison of the forced vibration response of multispan beam with different boundary conditions. 


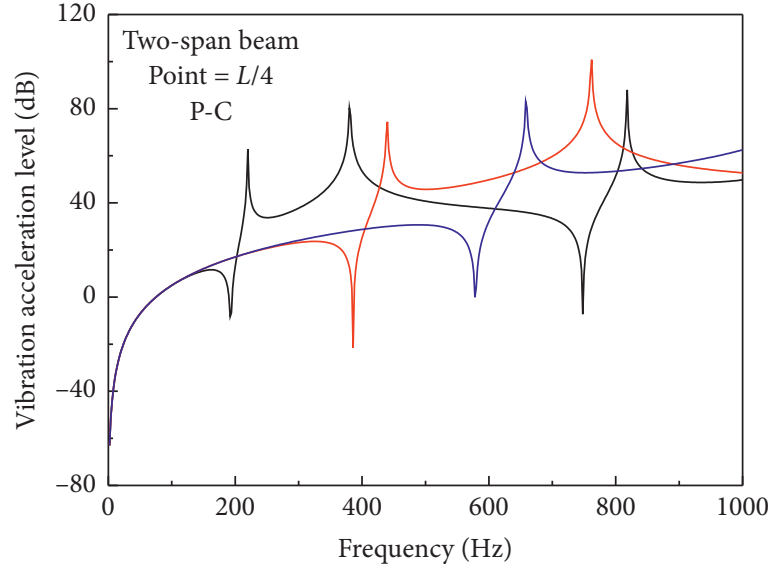

$\begin{aligned}-h / L & =0.02 \\ -h / L & =0.04 \\ h / L & =0.06\end{aligned}$

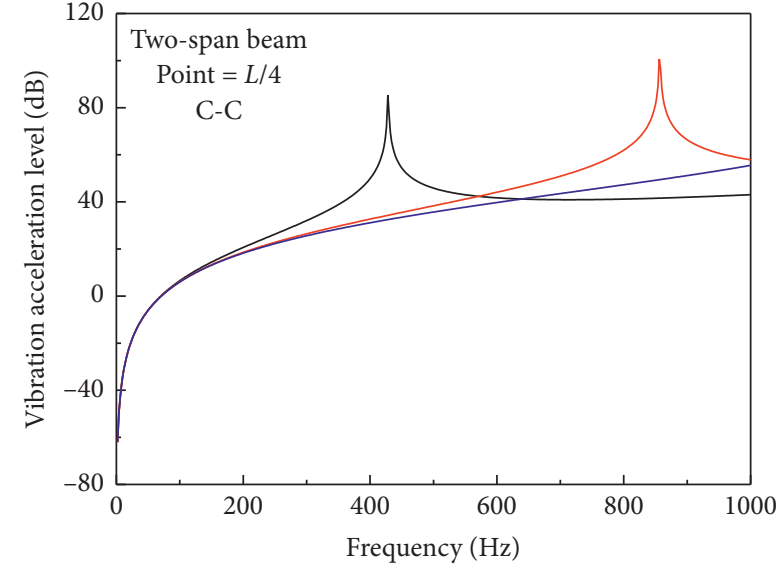

$\begin{aligned}-h / L & =0.02 \\ -h / L & =0.04 \\ -h / L & =0.06\end{aligned}$

(a)

(b)

FIGURE 16: Comparison of the forced vibration response of multispan beam with different $h / L$ ratios.

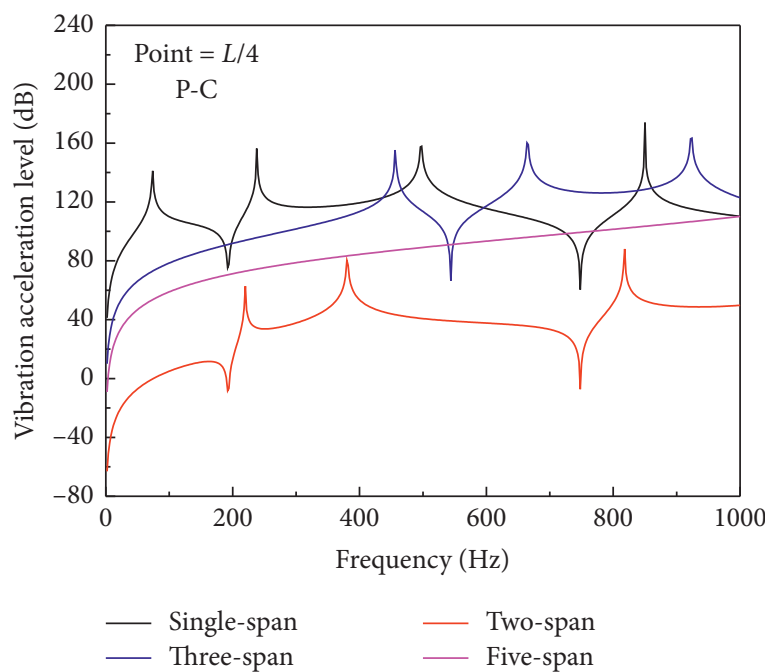

(a)

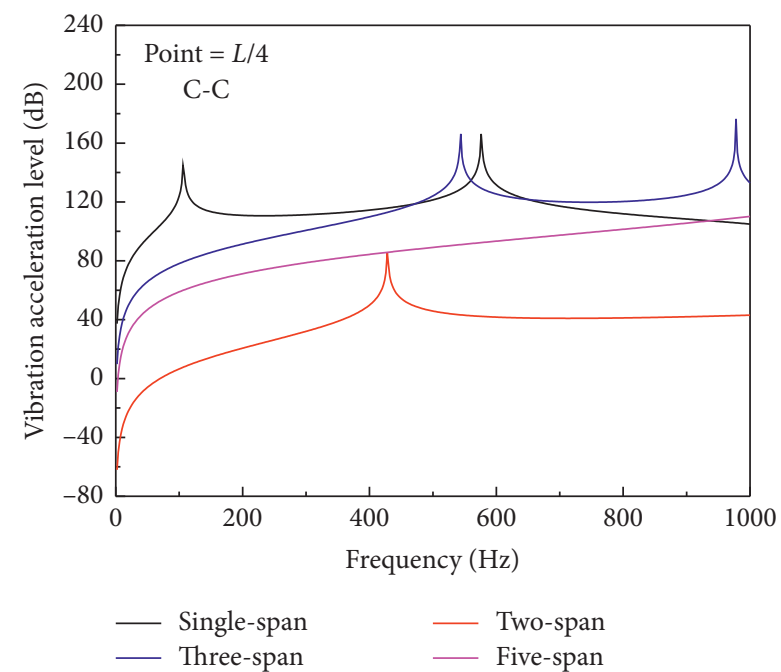

(b)

FIGURE 17: Comparison of the forced vibration response of multispan beam with different numbers of supporting springs.

increases, the number of forced vibration response peaks decreases in the low-frequency band, while the magnitude increases.

Lastly, Figures 17 and 18, respectively, display the comparison of the forced vibration response of multispan beam with different numbers and stiffness of supporting springs. It is indicated that the peak frequency shifts to the right with the numbers and stiffness of support springs increases, while the numbers of vibration response peaks decrease. At the same time, it can also be found that the response gradually decreases with the spring stiffness increases. 


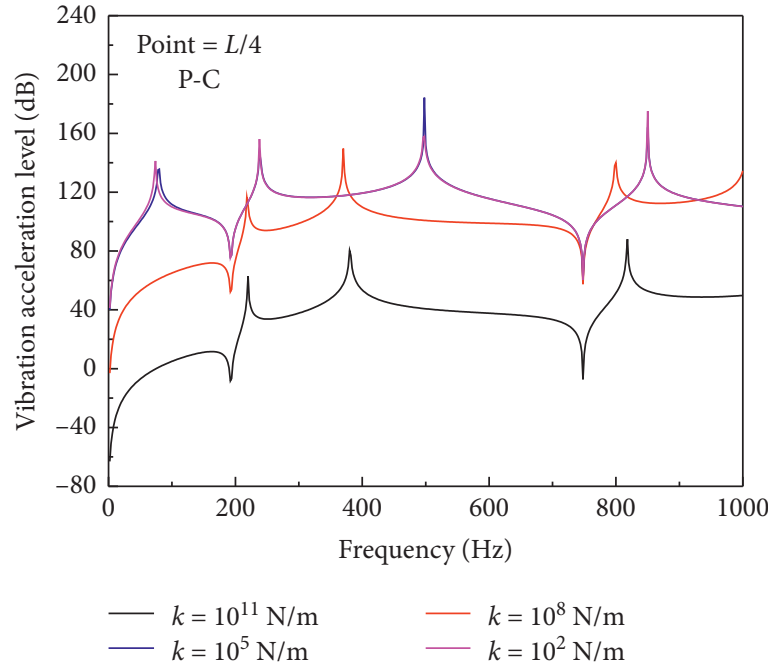

(a)

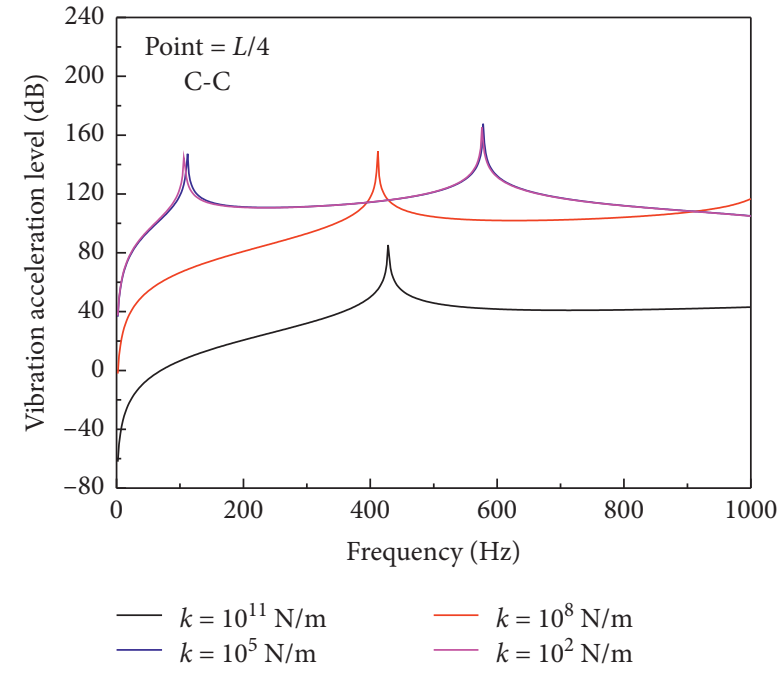

(b)

FIGURE 18: Comparison of the forced vibration response of two-span beam with different stiffness of supporting springs.

\section{Conclusions}

The free and forced vibration response of a multispan Timoshenko beam with different boundary restraints are studied by using the Ritz method in this paper. The domain decomposition approach is used to divide the structure to several equal sections, and two groups of springs (transversal displacement spring and rotational spring) are used to simulate different boundary restraints and continuity condition of the structure. In addition, several transversal displacement springs are arranged on the structure to represent the intermediate elastic support. Finally, the admissible displacement functions are expanded through Jacobi orthogonal polynomials, and the free and forced vibration characteristics of multispan beam structures can be obtained by using the Rayleigh-Ritz method. The accuracy of the current approach has been verified by comparing the results with existing literatures and FEM. The effects of transverse constraints spring and rotating constraints spring on the vibration characteristics of the structure are explored, which clearly shows that the effect of the transverse constraint spring on the vibration characteristics of the structure is greater than that of the rotation constraint spring. Besides this, results for various boundary conditions, ratios of $h / L$, numbers, and stiffness of supporting springs are presented, which shows that the geometric dimensions and restraint conditions have obvious influence on free and forced vibration characteristics of multispan beam. However, the paper only studies the free vibration and steady vibration of the continuous beam structure, which lacks the research on the transient vibration. At the same time, it needs to be studied for the more complex plate and shell structure, which will be the focus research of the future directions. In general, the research in this paper can be used as an extended application of Jacobi-Ritz method, and the research results of the paper can provide data support for engineers to conduct the structural design of infrastructure.

\section{Data Availability}

The data used to support the findings of this study are included within the article.

\section{Conflicts of Interest}

The authors declare that there are no conflicts of interest regarding the publication of this paper.

\section{Acknowledgments}

This study was funded by the National Natural Science Foundation of China (U2006229), National Key Research and Development Program (2016YFC0303406), Key Research and Development Program of Shandong Province (2019JZZY010125, 2020CXGC010701, and 2020CXGC010702), Ph.D. Student Research and Innovation Fund of the Fundamental Research Funds for the Central Universities (3072020GIP0102), Natural Basic Research Project of China (2019414C003), and Southern Marine Science and Engineering Guangdong Laboratory (Zhuhai) (311021013).

\section{References}

[1] A. Palatini and S. Timoshenko, Vibration Problems in Engineering, Wiley, Hoboken, NJ, USA, 1930.

[2] K. Torabi, M. Ghassabi, M. Heidari-Rarani et al., "Variational iteration method for free vibration analysis of a Timoshenko beam under various boundary conditions," International Journal of Engineering, vol. 30, no. 10, pp. 1565-1572, 2017.

[3] Y. C. Liu and C. S. Gurram, "The use of He's variational iteration method for obtaining the free vibration of an EulerBernoulli beam," Mathematical and Computer Modelling, vol. 50, no. 11-12, pp. 1545-1552, 2009.

[4] D. V. Bambill, C. A. Rossit, R. E. Rossi, D. H. Felix, and A. R. Ratazzi, "Transverse free vibration of non uniform rotating Timoshenko beams with elastically clamped 
boundary conditions," Meccanica, vol. 48, no. 6, pp. 1289-1311, 2013.

[5] M. Mohandes and A. R. Ghasemi, "Modified couple stress theory and finite strain assumption for nonlinear free vibration and bending of micro/nanolaminated composite Euler-Bernoulli beam under thermal loading," Proceedings of the Institution of Mechanical Engineers-Part C: Journal of Mechanical Engineering Science, vol. 231, no. 21, pp. 40444056, 2017.

[6] M. Boiangiu, V. Ceausu, and C. D. Untaroiu, "A transfer matrix method for free vibration analysis of Euler-Bernoulli beams with variable cross section," Journal of Vibration and Control, vol. 22, no. 11, pp. 2591-2602, 2016.

[7] Y. Kiani, "Analysis of FG-CNT reinforced composite conical panel subjected to moving load using Ritz method," ThinWalled Structures, vol. 119, pp. 47-57, 2017.

[8] Y. Kiani and M. Mirzaei, "Rectangular and skew shear buckling of FG-CNT reinforced composite skew plates using Ritz method," Aerospace Science and Technology, vol. 77, pp. 388-398, 2018.

[9] F. Z. Pang, H. C. Li, H. L. Chen, and Y. Shan, "Free vibration analysis of combined composite laminated cylindrical and spherical shells with arbitrary boundary conditions," Mechanics of Advanced Materials and Structures, vol. 28, pp. 1-18, 2019.

[10] H. Li, F. Z. Pang, X. H. Miao, and Y. H. Li, "Jacobi-Ritz method for free vibration analysis of uniform and stepped circular cylindrical shells with arbitrary boundary conditions: a unified formulation," Computers \& Mathematics with Applications, vol. 77, no. 7, pp. 427-440, 2019.

[11] F. Pang, H. Li, X. Wang, X. Miao, and S. Li, "A semi analytical method for the free vibration of doubly-curved shells of revolution," Computers \& Mathematics with Applications, vol. 75, no. 9, pp. 3249-3268, 2018.

[12] L.-l. Jing, P.-j. Ming, W.-p. Zhang, L.-r. Fu, and Y.-p. Cao, "Static and free vibration analysis of functionally graded beams by combination Timoshenko theory and finite volume method," Composite Structures, vol. 138, pp. 192-213, 2016.

[13] R. Balamuralikrishnan and R. J. Saravanan, "Effect of addition of alccofine on the compressive strength of cement mortar cubes," Emerging Science Journal, vol. 5, no. 2, pp. 155-170, 2021.

[14] F. Rahmani, R. Kamgar, and R. Rahgozar, "Finite element analysis of functionally graded beams using different beam theories," Civil Engineering Journal, vol. 6, no. 11, pp. 2086-2102, 2020.

[15] P. Rahgozar, "Free vibration of tall buildings using energy method and Hamilton's principle," Civil Engineering Journal, vol. 6, no. 5, pp. 945-953, 2020.

[16] Z. Chen, Z. Yang, N. Guo, and G. Zhang, “An energy finite element method for high frequency vibration analysis of beams with axial force," Applied Mathematical Modelling, vol. 61, pp. 521-539, 2018.

[17] S. Sinir, M. Cevik, and B. G. Sinir, "Nonlinear free and forced vibration analyses of axially functionally graded Euler-Bernoulli beams with non-uniform cross-section," Composites Part B: Engineering, vol. 148, pp. 123-131, 2018.

[18] S. D. Akbas, "Forced vibration responses of axially functionally graded beams by using Ritz method," Journal of Applied and Computational Mechanics, vol. 7, no. 1, pp. 109-115, 2021.

[19] H. J. Xiang and J. Yang, "Free and forced vibration of a laminated FGM Timoshenko beam of variable thickness under heat conduction," Composites Part B: Engineering, vol. 39, no. 2, pp. 292-303, 2008.
[20] Z. Wu and W. J. Chen, "Free and forced vibration of laminated composite beams," AIAA Journal, vol. 56, no. 7, pp. 2877-2886, 2018.

[21] R. Damghanian, K. Asemi, and M. Babaei, "A new beam element for static, free and forced vibration responses of microbeams resting on viscoelastic foundation based on modified couple stress and third-order beam theories," Iranian Journal of Science and Technology-Transactions of Mechanical Engineering, 2020.

[22] A. Paul and D. Das, "Non-linear forced vibration analysis of higher-order shear-deformable functionally graded material beam in thermal environment subjected to harmonic excitation and resting on non-linear elastic foundation," The Journal of Strain Analysis for Engineering Design, vol. 53, no. 6, pp. 446-462, 2018.

[23] H. Y. Lv and Y. M. Zhang, "A wave-based vibration analysis of a finite Timoshenko locally resonant beam suspended with periodic uncoupled force-moment type resonators," Crystals, vol. 10, no. 12, 2020.

[24] B. Qin, R. Zhong, Q. Wang, and X. Zhao, "A Jacobi-Ritz approach for FGP beams with arbitrary boundary conditions based on a higher-order shear deformation theory," Composite Structures, vol. 247, Article ID 112435, 2020.

[25] Z. Su, G. Y. Jin, and T. G. Ye, "Vibration analysis and transient response of a functionally graded piezoelectric curved beam with general boundary conditions," Smart Materials and Structures, vol. 25, no. 6, 2016.

[26] C. Johansson, C. Pacoste, and R. Karoumi, "Closed-form solution for the mode superposition analysis of the vibration in multi-span beam bridges caused by concentrated moving loads," Computers \& Structures, vol. 119, pp. 85-94, 2013.

[27] H. Fakhreddine, A. Adri, S. Rifai, and R. Benamar, "Geometrically nonlinear free and forced vibrations of Euler-Bernoulli multi-span beams," in Proceedings of the 14th International Conference on Vibration Engineering and Technology of Machinery (Vetomac Xiv), vol. 211, Lisbon, Portugal, September 2018.

[28] A. Ghannadiasl and S. Khodapanah Ajirlou, "Forced vibration of multi-span cracked Euler-Bernoulli beams using dynamic Green function formulation," Applied Acoustics, vol. 148, pp. 484-494, 2019.

[29] G. Chen, X. Zeng, X. Liu, and X. Rui, “Transfer matrix method for the free and forced vibration analyses of multi-step Timoshenko beams coupled with rigid bodies on springs," Applied Mathematical Modelling, vol. 87, pp. 152-170, 2020.

[30] H. P. Lin and S. C. Chang, "Free vibration analysis of multispan beams with intermediate flexible constraints," Journal of Sound and Vibration, vol. 281, no. 1-2, pp. 155-169, 2005.

[31] H. B. Liu, H. H. Nguyen, and Y. M. Xiang, "Vibration analysis of a multi-span continuous beam with cracks," Advances in Civil Engineering, vol. 256-259, no. 1-4, pp. 964-972, 2013.

[32] J. Lee, "Free vibration analysis of circularly curved multi-span Timoshenko beams by the pseudospectral method," Journal of Mechanical Science and Technology, vol. 21, no. 12, pp. 2066-2072, 2007.

[33] T. V. Lien, N. T. Duc, and N. T. Khiem, "Free and forced vibration analysis of multiple cracked FGM multi span continuous beams using dynamic stiffness method," Latin American Journal of Solids and Structures, vol. 16, no. 2, 2019.

[34] X. H. Lv, D. Y. Shi, Q. S. Wang et al., "A unified solution for the in-plane vibration analysis of multi-span curved Timoshenko beams with general elastic boundary and coupling conditions," Journal of Vibroengineering, vol. 18, no. 2, pp. 1071-1087, 2016. 
[35] Y. Yesilce, "Free and forced vibrations of an axially-loaded Timoshenko multi-span beam carrying a number of various concentrated elements," Shock and Vibration, vol. 19, no. 4, pp. 735-752, 2012.

[36] Y. Yesilce and O. Demirdag, "Effect of axial force on free vibration of Timoshenko multi-span beam carrying multiple spring-mass systems," International Journal of Mechanical Sciences, vol. 50, no. 6, pp. 995-1003, 2008.

[37] Y. Yesilce, O. Demirdag, and S. Catal, "Free vibrations of a multi-span Timoshenko beam carrying multiple spring-mass systems," Sadhana, vol. 33, no. 4, pp. 385-401, 2008.

[38] Z. Zhao, S. Wen, and F. Li, "Vibration analysis of multi-span lattice sandwich beams using the assumed mode method," Composite Structures, vol. 185, pp. 716-727, 2018.

[39] Z. Zhao, S. Wen, F. Li, and C. Zhang, "Free vibration analysis of multi-span Timoshenko beams using the assumed mode method," Archive of Applied Mechanics, vol. 88, no. 7, pp. 1213-1228, 2018.

[40] H.-Y. Lin and Y.-C. Tsai, "Free vibration analysis of a uniform multi-span beam carrying multiple spring-mass systems," Journal of Sound and Vibration, vol. 302, no. 3, pp. 442-456, 2007.

[41] Y. Yesilce, "Effect of axial force on the free vibration of reddybickford multi-span beam carrying multiple spring-mass systems," Journal of Vibration and Control, vol. 16, no. 1, pp. 11-32, 2010.

[42] Y. Yesilce, "Free vibrations of a Reddy-Bickford multi-span beam carrying multiple spring-mass systems," Shock and Vibration, vol. 18, no. 5, pp. 709-726, 2011.

[43] F. Z. Pang, C. Gao, J. Cui, Y. Ren, H. Li, and H. C. Wang, "A semianalytical approach for free vibration characteristics of functionally graded spherical shell based on first-order shear deformation theory," Shock and Vibration, vol. 2019, Article ID 7352901, 18 pages, 2019.

[44] D. Shi, Q. Wang, X. Shi et al., "An accurate solution method for the vibration analysis of Timoshenko beams with general elastic supports," Journal of Mechanical Engineering Science, vol. 203-210, pp. 418-424, 2014.

[45] Q. Wang, K. Choe, J. Tang et al., "Vibration analyses of general thin and moderately thick laminated composite curved beams with variable curvatures and general boundary conditions," Mechanics of Advanced Materials \& Structures, vol. 27, pp. 1-15, 2019.

[46] F. Pang, H. Li, J. Cui, Y. Du, and C. Gao, "Application of flügge thin shell theory to the solution of free vibration behaviors for spherical-cylindrical-spherical shell: a unified formulation," European Journal of Mechanics-A: Solids, vol. 74, pp. 381-393, 2019.

[47] H. Li, F. Pang, and H. Chen, "A semi-analytical approach to analyze vibration characteristics of uniform and stepped annular-spherical shells with general boundary conditions," European Journal of Mechanics-A: Solids, vol. 74, pp. 48-65, 2019.

[48] M. e. S. Sari and E. A. Butcher, "Free vibration analysis of nonrotating and rotating Timoshenko beams with damaged boundaries using the Chebyshev collocation method," International Journal of Mechanical Sciences, vol. 60, no. 1, pp. 1-11, 2012. 